Article

\title{
Retrieval of Melt Pond Fraction over Arctic Sea Ice during 2000-2019 Using an Ensemble-Based Deep Neural Network
}

\author{
Yifan Ding ${ }^{1,4,5} \oplus$, Xiao Cheng ${ }^{1,2,4,5, *}$, Jiping Liu ${ }^{3}$, Fengming Hui ${ }^{1,2,4,5}$, Zhenzhan Wang ${ }^{6}(\mathbb{D}$ and \\ Shengzhe Chen ${ }^{3}$ \\ 1 College of Global Change and Earth System Science, and State Key Laboratory of Remote Sensing Science, \\ Beijing Normal University, Beijing 100875, China; yfding@mail.bnu.edu.cn (Y.D.); \\ huifm@mail.sysu.edu.cn (F.H.) \\ 2 School of Geospatial Engineering and Science, Sun Yat-sen University, Zhuhai 519000, China \\ 3 Department of Atmospheric and Environmental Sciences, University at Albany, State University of \\ New York, Albany, NY 12222, USA; jliu26@albany.edu (J.L.); schen26@albany.edu (S.C.) \\ 4 Southern Marine Science and Engineering Guangdong Laboratory (Zhuhai), Zhuhai 519000, China \\ 5 University Corporation for Polar Research, Beijing 100875, China \\ 6 Key Laboratory of Microwave Remote Sensing, National Space Science Center, Chinese Academy \\ of Sciences, Beijing 100875, China; wangzhenzhan@mirslab.cn \\ * Correspondence: chengxiao9@mail.sysu.edu.cn
}

Received: 15 July 2020; Accepted: 22 August 2020; Published: 25 August 2020

\begin{abstract}
The accurate knowledge of variations of melt ponds is important for understanding the Arctic energy budget due to its albedo-transmittance-melt feedback. In this study, we develop and validate a new method for retrieving melt pond fraction (MPF) over Arctic sea ice using all seven spectral bands of MODIS surface reflectance. We construct a robust ensemble-based deep neural network and use in-situ MPF observations collected from multiple sources as the target data to train the network. We examine the potential influence of using sea ice concentration (SIC) from different sources as additional target data (besides MPF) on the MPF retrieval. The results suggest that the inclusion of SIC has a minor impact on MPF retrieval. Based on this, we create a new MPF data from 2000 to 2019 (the longest data in our knowledge). The validation shows that our new MPF data is in good agreement with the observations. We further compare the new MPF dataset with the previously published MPF datasets. It is found that the evolution of the new MPF is similar to previous MPF data throughout the melting season, but the new MPF data is in relatively better agreement with the observations in terms of correlations and root mean squared errors (RMSE), and also has the smallest value in the first half of the melting season.
\end{abstract}

Keywords: melt pond fraction; Arctic sea ice; deep neural network

\section{Introduction}

The onset of the melting season, typically in late spring, is driven by the increase in incoming solar radiation and weather systems originating in the mid-latitudes. As snow and ice melts, the melt water accumulates on the surface in valleys of sea ice topography. The area and depth of the ponds depend on sea ice topography and internal structure. Field experiments showed that melt ponds are smaller and deeper on multiyear ice (MYI), but wider and shallower on seasonal sea ice (e.g., [1-5]). Melt ponds have lower albedo than snow and bare ice (e.g., [4,6-8]). This increases the absorption of solar radiation and further melts the snow and ice, leading to an important positive albedo feedback [8-11]. There are several stages of the evolution of sea ice albedo with melt ponds from May to September $[4,12,13]$. 
The albedo drops to $\approx 0.6$ in the early stage associated with snow melt, and then further decreases to $\approx 0.32$ associated with the formation of melt ponds. As the pond drainage happens, the albedo slightly increases to $\approx 0.54$. In late July to August, as melt ponds evolve steadily, the albedo decreases by $\approx 0.0083 \mathrm{~d}^{-1}$ [4]. In this stage, the albedo of mature ponded ice is generally below 0.3 and even lower than 0.2 for seasonal sea ice $[4,13,14]$. Starting in mid-August, as the melt ponds freeze up, the albedo gradually increases as snow falls and temperature decreases. The evolution of melt ponds is governed by complex processes, including interactions with the snow layer, drainage rates through permeable sea ice and episodic refreezing $[3,5,15]$.

Melt ponds also lead to higher fraction of solar radiation being transmitted through sea ice during the melting season. Large-scale under ice light measurements using a remotely operated vehicle under summer Arctic sea ice showed that the first-year ice (FYI) extensively covered by melt ponds not only allows three times as much light to pass through than that of MYI, but also absorbs $\approx 50 \%$ more solar radiation $[16,17]$. The light transmitted through the ponded ice warms sea water under the ice, and thus enhances the ice melt. This can also increase primary productivity in the upper ocean $[18,19]$. Therefore, the knowledge of the distribution and evolution of melt ponds is of great importance for understanding the Arctic energy budget.

The Arctic has experienced amplified warming and extensive sea ice retreat in recent decades [20-22]. The seasonal sea ice minimum has declined by $12.4 \%$ per decade for the period of 1979-2010 [23]. The variability of sea ice extent in recent years is much stronger than before [22]. The decline of sea ice extent and area of the entire ice cover in recent years is accelerated compared to that during 1979-1996 [24]. According to the observations by NSIDC, Arctic sea ice extent reached its historic low in 2012. Previous work by Serreze and Stroeve [25] suggests that though the decreasing trend is steepening in a warming climate, the annual sea ice extent is also related to the inherent large variability in summer atmospheric circulation patterns and the oceanic heat loss in winter. The recovery sea ice extent in 2013 and 2014 is related to the summer weather conditions which enabled a large fraction of the thin ice to survive. The interannual variability of sea ice extent in long term trend is hard to predict [25]. Due to the rapid decline of Arctic sea ice, the demand for more information of its physical and thermal properties is increasing. In recent years, extensive melt pond coverage has been observed during the melting season [26-28], which can lead to a positive albedo-transmittance-melt feedback, partly contributing to the observed sea ice loss. Recent studies suggested the amount of MPF over Arctic sea ice can be used to improve the skill of summer Arctic sea ice prediction [29,30]. Thus, accurate knowledge of variation of melt ponds in the Arctic is extremely important for understanding and predicting sea ice changes.

Although melt ponds play an important role in the Arctic climate system, observations of melt ponds are far from adequate for the Arctic Ocean. Some progress on the derivation of MPF using remote sensing has been noted. Yackel et al. [1] used the Radarsat-1 SAR images to examine the evolution of melt ponds in the Canadian Archipelago and found a significant correlation between the microwave scattering coefficients and the MPF. Using the Landsat-7 data, a case study was conducted to retrieve ice surface conditions in Baffin Bay in June 2000 [31]. The results showed that melt ponds have different appearance relative to dry and wet ice in the Landsat true-color image, which helps to distinguish melt ponds from sea ice. The MPF derived by the Landsat 7 has a correlation of 0.68 with the aerial observation [32]. Tschudi et al. [14] acquired the spectral reflectance of different ice types (pond, ice, snow covered ice, and open water) over three Moderate Resolution Image Spectroradiometer (MODIS) channels near Barrow, Alaska and retrieved the MPF over the Beaufort and Chukchi Seas for summer 2004 based on a mixed-pixel algorithm, which provides important guidance to further retrieval of the pond fraction in the entire Arctic. Based on this, Rösel et al. [33] developed a 8-day interval Arctic-wide MPF data using the MODIS surface reflectance data. This product showed that the averaged MPF increases quickly from mid-May to late June, reaches the peak value in late June and early July, and then decreases gradually. However, the retrieval algorithm used by Rösel et al. [33] depends on the prescribed spectral reflectance of surface ice types, which can cause uncertainties due to the changing 
physical properties of ice, snow, and melt ponds during the melting season. A more recent study [34] suggested that, due to the constant spectral reflectance of each surface type, the "spectral unmixing" method in Rösel et al. [33,35] has limitations in MPF retrieval, especially for the MPF over entire Arctic in long-term trends. The MPF retrieved by "spectral unmixing" needs to be improved for validating melt pond models or establishing unambiguous long-term trends. Istomina et al. [36] developed another MPF data using the Medium Resolution Imaging Spectrometer (MERIS) data, including the radiance coefficients as well as solar and observation angles. The improvement of the algorithm is that it does not depend on the priori reflectance of different ice types. They used an analytical solution of sea ice surface reflection and a radiative transfer model [37]. Although the retrieval partly avoids the problem of prior fixed reflectance, the retrieved MPF is not accurate for dark pond fraction and only covers part of the Arctic. Some attempts have been made to obtain pond information in small scale using SAR imagery. Kim et al. [38] conducted a helicopter based airborne survey in the northern of Chukchi Sea in summer 2011 and obtained the MPF using $0.3 \mathrm{~m}$ resolution SAR images. Scharien et al. $[39,40]$ pointed out the potential detection of MPF on FYI using co-polarization SAR data. Mäkynen et al. [41] analyzed the pond evolution over the area of the Fram Strait, Greenland, and Svalbard from June to August in 2009 using ENVISAT WSM images with HH-polarization. Han et al. [42] retrieved the MPF on MYI using TerraSAR-X dual-polarization in the Chukchi Sea and western Arctic. Li et al. [43] used the hybrid-polarized co-polarization SAR imagery to retrieve MPF on FYI in the central Canadian Arctic Archipelago from May to June 2012. However, it is difficult to obtain Arctic-wide MPF over long periods based on SAR image due to the limitation of the data acquisition. The MPF retrieval was also conducted using AMSR-E passive microwave data [44]. They suggested that in many regions, the difference of the averaged MPF between the MODIS retrieval and AMSR-E retrieval during 2002-2011 is less than 5\% [44]. The smallest melt pond that remote sensing instruments can detect mostly depend on the resolution of the data, i.e., the smallest scale of melt pond that can be detected is tens of meters for Landsat 7 and Radarsat- 1 , and meter to decimeter for the airborne SAR and some of the satellite-based observations in high resolution $[8,45]$. These observations can help capture detailed ice features. For the other instruments like MODIS and MERIS with relatively coarser resolution (hundred to thousand meters), it is difficult to define the smallest melt ponds that can be detected, since it is also related to the retrieval methods.

The artificial neural network (ANN) has been widely used for the classification of remote sensing images over various surfaces [46-48]. It has been recently employed to retrieve sea ice parameters. It is shown that the ANN has the potential to learn the relationship between sea ice parameters and input data $[33,49,50]$. More recently, Liu et al. [49] tested an alternative way for the MPF retrieval in summer 2008 by using the ANN. The visible imagery from the National Snow and Ice Data Center (NSIDC) in summer 2000 and 2001 are used as prior knowledge for the network training. However, they only used a single data set as prior knowledge for the network training and one network to obtain the relationship with MPF, which might lead to large uncertainty. Deep neural network (DNN) with multiple hidden layers, stemmed from the neural network theory, helps establish better relationships, particularly nonlinear relationships between the input and the target relative to the linear regression methods, i.e., Liu et al. [51] used the DNN to retrieve snow depth over Arctic sea ice based on the brightness temperatures at different passive microwave frequencies, which shows better results than those using the regression. This suggests the DNN can lead to better data representation learning, holding great promise to address the challenges of the melt pond retrieval.

In this study, we develop a new dataset of MPF over Arctic sea ice based on an ensemble-based DNN. As aforementioned, the previous two MPF datasets [35,36] based on MODIS and MERIS are not continued (spinning from 2000 to 2011 for MODIS and 2002 to 2011 for MERIS). The new MPF dataset covers the period of 2000-2019. We validate the retrieved MPF against the collected observations from multiple sources and compare this new dataset with the previously published MPF datasets to demonstrate its reliability. 


\section{Materials and Methods}

\subsection{MODIS Surface Reflectance Data}

In this study, the MODIS/Terra Surface Reflectance 8-Day L3 version 6 (MOD09A1, [52]) was used to train the network and derive the MPF dataset over Arctic sea ice. The MOD09A1 has a spatial resolution of $500 \mathrm{~m}$ in the Sinusoidal projection and is available at 8-day interval. In MOD09A1, each pixel contains the relatively best possible L2G (Level 2 gridded data) observation during an 8-day period. Each orbit observation is assigned a score, based on whether it is flagged for cloud, cloud shadow, high aerosol or low aerosol, or contains high view angle or low solar zenith angle. The lowest score, 0 , is assigned to observations with fill values for data. The remaining scores are set from 1 (BAD) to 10 (GOOD) based on the aforementioned factors (see the MODIS Surface Reflectance User's Guide Collection 6 at https://lpdaac.usgs.gov/documents/306/MOD09_User_Guide_V6.pdf for details). Here we evaluate the scores of the MOD09A1 data used in the network. The results show that $98.9 \%$ of MOD09A1 data are in the highest quality (score $=10$ ) and others are in good quality (score $=9$ or 8). In this study, the reasons we use the MOD09A1 to derive the MPF are on one hand to minimize the effect of the clouds on the spectral reflectance (MOD09A1 selects the observation with the highest score and the lowest view angle), and on the other hand to make our MPF dataset comparable to the previous MPF dataset [35] in terms of time interval.

We used surface reflectance from all seven spectral bands (bands 1-7) of MOD09A1 version 6 to retrieve the MPF over Arctic sea ice. The wavelengths for the seven bands are 620-670 nm (band 1), 841-876 nm (band 2), 459-479 nm (band 3), 545-565 nm (band 4), 1230-1250 nm (band 5), 1628-1652 nm (band 6), and 2105-2155 nm (band 7). Previous study by Rösel et al. [33,35] used three spectral bands from MOD09A1 version 5 in the MPF retrieval.

\subsection{MPF Measurements for Network Training}

A number of melt pond surveys have been conducted in the Arctic. Figure 1 shows the geographical distribution of all the MPF measurements used in this study. The observations can be classified into two groups. The first group has the resolution of the observations that are below $1 \times 1 \mathrm{~km}$. The second group has the resolution of the observations that are above $1 \times 1 \mathrm{~km}$. Only the observations in the first group were used as the training data in the DNN, since they have relatively comparable resolution as the MODIS data. The MPF in the first group are collected from satellite-based, airborne, ship-based, and in-situ observations from the following eight sources. Table 1 summarizes the information of the MPF observations used in the DNN training. The total number of the observations (hereafter referred as Num. Obs) used in the DNN training is 8398. The observations were collected during June to September from 2000 to 2018. The detailed description of each observation is provided below. 


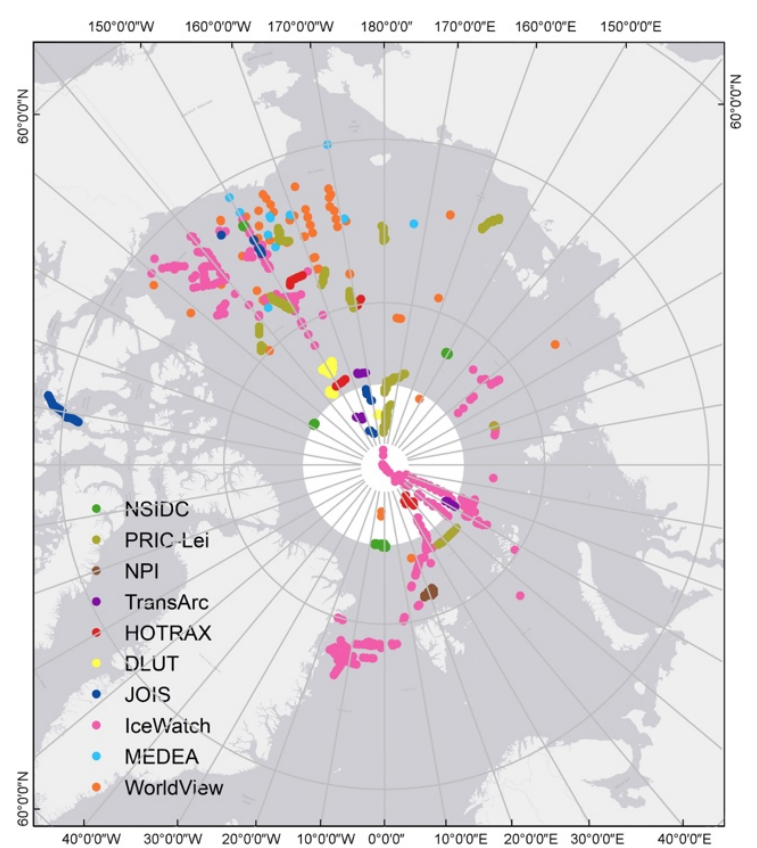

Figure 1. The geographical distribution of the observed MPF from multiple sources. The base map was developed by Esri using HERE data, Garmin basemap layers, OpenStreetMap contributors, Esri basemap data, and data from the GIS user community.

Table 1. Information of MPF observations used in network training.

\begin{tabular}{|c|c|c|c|c|}
\hline Source & Num. Obs & Time Range & Latitude Range & Spatial Resolution \\
\hline NSIDC & 3202 & $\begin{array}{l}\text { Jun-Aug 2000, } \\
\text { Jun-Aug } 2001\end{array}$ & $72.8^{\circ}-85.1^{\circ} \mathrm{N}$ & $500 \mathrm{~m} \times 500 \mathrm{~m}$ \\
\hline PRIC-Lei & 691 & $\begin{array}{c}\text { Jul-Aug 2010, } \\
\text { Aug-Sep 2012, } \\
\text { Aug 2014, } \\
\text { Jul-Aug 2016 }\end{array}$ & $71.7^{\circ}-88.4^{\circ} \mathrm{N}$ & $1 \mathrm{~km} \times 1 \mathrm{~km}$ \\
\hline NPI & 1387 & Jul-Aug 2012 & $81.4^{\circ}-82.7^{\circ} \mathrm{N}$ & $60 \mathrm{~m} \times 40 \mathrm{~m}$ \\
\hline TransArc & 8 & Aug-Sep 2011 & $83.1^{\circ}-86.3^{\circ} \mathrm{N}$ & $50 \mathrm{~m} \sim 1 \mathrm{~km}$ (visibility) \\
\hline HOTRAX & 156 & Aug-Sep 2005 & $74.4^{\circ}-86.1^{\circ} \mathrm{N}$ & $57 \mathrm{~m} \times 70 \mathrm{~m}$ \\
\hline DLUT & 2503 & $\begin{array}{c}\text { Aug-Sep 2008, } \\
\text { Jul-Aug } 2010\end{array}$ & $71.9^{\circ}-89.0^{\circ} \mathrm{N}$ & $\begin{array}{c}98 \mathrm{~m} \times 67 \mathrm{~m}, \\
147 \mathrm{~m} \times 100 \mathrm{~m}, \\
490 \mathrm{~m} \times 350 \mathrm{~m}\end{array}$ \\
\hline IceWatch & 58 & $\begin{array}{c}\text { Aug-Sep 2012, } \\
\text { Aug 2013, } \\
\text { Jul-Sep 2014, } \\
\text { Aug 2015, } \\
\text { Jul-Aug 2018 }\end{array}$ & $71.4^{\circ}-89.9^{\circ} \mathrm{N}$ & $50 \mathrm{~m} \sim 1 \mathrm{~km}$ (visibility) \\
\hline JOIS & 393 & Jul-Sep 2011 & $68.9^{\circ}-88.2^{\circ} \mathrm{N}$ & $1453 \mathrm{~m}^{2} \sim 2397 \mathrm{~m}^{2}$ \\
\hline Total Num. Obs & 8398 & & & \\
\hline
\end{tabular}

- NSIDC: The MPFs were obtained from the NSIDC during summer of 2000 and 2001 [53]. Development of this data set was based on experience gained using reconnaissance imagery during the Surface Heat Budget of the Arctic Ocean (SHEBA) and earlier summer ice monitoring experiments $[54,55]$. Visible band imagery was analyzed using supervised maximum likelihood classification to derive either two (water and ice) or three (pond, open water, and ice) surface classes. The estimated pond coverage was under $500 \mathrm{~m}$ square cells within $10 \mathrm{~km}$ square images (image resolution is $1 \mathrm{~m}$ ). The NSIDC MPF used in the network training was measured at 
72.8-85.1 $1^{\circ} \mathrm{N}$ from June to August in 2000 and 2001. The coverage of each MPF estimation is $500 \times 500 \mathrm{~m}$. The measurement from NSIDC is the MPF relative to grid (the coverage of each observation). The data can be found at https://nsidc.org/data/G02159/versions/1.

- PRIC-Lei: MPFs were collected during the Arctic Research Expeditions by the Polar Research Institute of China (PRIC) in summer from 2010 to 2016 [56]. Half-hourly Arctic Shipborne Sea Ice Standardization Tool (ASSIST) observations were conducted at the bridge of the R/V Xuelong to document ice conditions, including sea ice concentration (SIC), snow thickness, fractions of melt ponds, dirty ice, ridging, and floe size. SIC was only assessed for a local area with a diameter of 1-2 $\mathrm{km}$ and MPF was estimated around the ship within $1 \mathrm{~km}$. The MPF of PRIC-Lei used in the network training was measured along the cruise at $71.7^{\circ}-88.4^{\circ} \mathrm{N}$ from July to September in 2010 , 2012,2014 , and 2016. The coverage of each MPF record is about $1 \times 1 \mathrm{~km}$. The measurement from PRIC-Lei is MPF relative to ice-covered area. The data could be obtained by contacting the first author in Lei et al. [56].

- NPI: The MPFs were collected by the Norwegian Polar Institute (NPI) during the field campaign on Arctic sea ice north of Svalbard in summer 2012 [57,58]. The data set presents regional scale of about $150 \mathrm{~km}$ morphological properties of a relatively thin, 70-90 cm modal thickness, first-year Arctic sea ice pack in an advanced stage of melt. The data comprise fractions of three surface types (bare ice, melt ponds, and open water) along the flight tracks calculated from images acquired by a helicopter-borne camera system. The NPI MPF used in the network training was measured at $81.4-82.7^{\circ} \mathrm{N}$ during late July to early August in 2012. The coverage (footprint) of each MPF record is about $60 \times 40 \mathrm{~m}$. The obtained measurement from NPI is the MPF relative to ice-covered area. The data can be found at https://data.npolar.no/dataset/5de6b1e4-b62f-4bd4-889c-8eb7bb862d3b.

- TransArc: MPFs were collected from the ice breaker RV Polarstern during the Germany Trans-Polar cruise ARKXXVI/3 [59]. The TransArc was conducted from August to October 2011. Visual observations of sea ice conditions were performed hourly from the bridge of Polarster. Sea ice type and thickness, snow depth, pond coverage, and surface scattering layer depth were recorded during the cruise. The MPF observations were based on the ASPeCT protocol. It should be noted that the TransArc MPF was recorded on multiyear and first-year ice, respectively, for some cases, the MPF was estimated by using the linear mix of these values. The visibility in TransArc ranges between $50 \mathrm{~m}$ and $10 \mathrm{~km}$ based on ASPeCT. The TransArc MPF used in the network training was measured at $83.1^{\circ}-86.3^{\circ} \mathrm{N}$ from August to September in 2011 and the visibility of the records ranges from $50 \mathrm{~m}$ to $1 \mathrm{~km}$. The obtained measurement from TransArc is the MPF relative to ice-covered area. The data can be found at https://doi.pangaea.de/10.1594/PANGAEA.803312.

- HOTRAX: MPFs were collected during the Healy Oden Trans-Arctic Expedition (HOTRAX) by the Polar Science Center, University of Washington [60]. The HOTRAX was conducted from August to September 2005 to obtain physical properties of the ice pack. The ice survey was made based on ice station measurements, helicopter survey flights, and the deployment of autonomous ice mass balance buoys. The MPFs from HOTRAX used in the network training were measured at $74.4^{\circ}-86.1^{\circ} \mathrm{N}$ from August to September 2005. The coverage of each MPF measurement is about $57 \times 70 \mathrm{~m}$. The obtained measurement from HOTRAX is the MPF relative to the grid (the coverage of each observation). The data could be obtained by contacting the first author in Perovich et al. [60].

- DLUT: MPFs were collected during two Chinese Arctic Research Expeditions by the Dalian University of Technology (DLUT) [26,61]. The first survey of DLUT was conducted from July to September 2008 during the third Chinese Arctic Research Expedition. During the cruise, eight helicopter flights were conducted, and more than 9000 aerial images were obtained in the Pacific sector of the Arctic. Each image covers an area of approximately $98 \times 67 \mathrm{~m} \mathrm{[61].}$ The second survey of DLUT was conducted from July to September 2010 using underway shipand helicopter-based ice observations. The images were classified into three surface categories (sea ice/snow, water, and melt ponds). The flight altitude varied between 150 and $500 \mathrm{~m}$. Each image 
covers an area between $147 \times 100 \mathrm{~m}$ and $490 \times 335 \mathrm{~m}$ [26]. The images from the two cruises are spaced without overlapping, and each image represents an independent scene. The DLUT MPF used in the network training was measured at $71.9^{\circ}-81.0^{\circ} \mathrm{N}$ during August to September 2008 and July to September 2010. The coverage of each MPF estimated from the airborne image is about 98 $\times 67 \mathrm{~m}$ or ranges from $147 \times 100 \mathrm{~m}$ to $490 \times 335 \mathrm{~m}$. The obtained measurement from DLUT is the MPF relative to the grid (image area). The data could be obtained by contacting the first author in Lu et al. [61] and Huang et al. [26].

- IceWatch: The MPFs were collected from the IceWatch community. Ice Watch is a program coordinating visual observations of sea ice conducted from ships in the northern hemisphere. Several parameters related to ice conditions are recorded using the ASSIST tool, including ice types, SIC, snow depth, MPF, melt pond depth. The MPF used in the network training was measured at $71.4^{\circ}-89.9^{\circ} \mathrm{N}$ from several cruises during August to September 2012, August 2013, July to September 2014, August 2015, and July to August 2018. The visibility of the observations ranges from $50 \mathrm{~m}$ to $10 \mathrm{~km}$. Here we only use the observations with visibility below $1 \mathrm{~km}$ in the network training. The obtained measurement from IceWatch is the MPF relative to ice-covered area. The data can be found at https://icewatch.met.no/.

- JOIS: The MPFs were collected from the ship-based observations by Joint Ocean Ice Study (JOIS). The JOIS was conducted during 2003-2014 on the Canadian Coast Guard Ship Louis S. St-Laurent [44]. The cameras were mounted with a view of the horizon and ice pack in front of the ship. The images were classified into five types (water only; ice only; water and ice; pond and ice; water, pond, and ice). Due to the camera malfunction and some bad ice conditions, information was missing in some years [44]. The MPF used in the network training was measured at $68.9-88.2^{\circ} \mathrm{N}$ during July to September 2011. The covered areas of per image range from 1453 to $2397 \mathrm{~m}^{2}$. The obtained measurement from JOIS is the MPF relative to the grid (image area). The data could be obtained by contacting the first author in Tanaka et al. [44].

Figures S1-S8 also show the map-based cases of the above MPF observations overlaid on the NASA Team SIC [62]. It appears that most of the MPF observations are in the grids with SIC above $40 \%$.

\subsection{MPF Measurements for Independent Validation}

We also used two additional satellite-based observations as the independent validation data in this study. The geographical distribution is shown in Figure 1. Note: the observations from IceWatch and TransArc (visibility of $\approx 10 \mathrm{~km}$ ) were also used as independent validation, since these observations are not used in the network training.

- MEDEA: The MPFs were retrieved by the Polar Science Center, University of Washington based on the classified high-resolution ( $1 \mathrm{~m}$ resolution) visible band satellite images following Webster et al. [8]. The MPFs were measured at $69-86.5^{\circ} \mathrm{N}$ over the Beaufort Sea, Chukchi Sea, the Canadian Arctic, the Fram Strait, and the East Siberian Sea from May to August for the period of 1999-2014. The scene size (square grid) of the MPFs ranges from 5 to $25 \mathrm{~km}$. In validation, we used the observations from June to August during 2000-2011. The obtained measurement from MEDEA is the MPF relative to ice-covered area. In validation, the MPF was transferred to the fraction relative to the grid (image area) using the measured SIC from MEDEA. The data can be found at http://psc.apl.uw.edu/melt-pond-data/.

- WorldView: The MPFs were collected from the WorldView satellite imagery during 2010-2015 by Wright and Polashenski [63]. The high resolution (0.46 and $1.84 \mathrm{~m}$ resolution) WorldView optical satellite imagery is able to capture the evolution of the ice and ocean surface state directly [45]. This dataset contains the results from processing the WorldView imagery of sea ice using an Open Source Sea-Ice Processing algorithm [45]. This method classifies surface coverage into three main categories: snow and bare ice; melt ponds and submerged ice; open water. Tests show the classification accuracy of this method typically exceeds $96 \%$ [45]. The recorded data covers 
from March to August during 2010-2015. The coverage of the WorldView imagery ranges from 77 to $728 \mathrm{~km}^{2}$. In validation, we used the observations from May to August during 2010-2015. The obtained measurement from WorldView is the MPF relative to the grid (image area). The data can be found at https://arcticdata.io/catalog/view/doi:10.18739/A22Z12P4J.

Figure S9 shows the SIC conditions for the above two MPFs using scatter plots. The results suggest that the MPF from MEDEA are mainly measured at SIC above $60 \%$, and the MPF above $10 \%$ from WorldView are mainly measured at SIC above $40 \%$.

\subsection{Method}

\subsubsection{Ensemble-Based Deep Neural Network}

In this study, we constructed an ensemble-based DNN to retrieve the MPF.

First, we processed the data to co-locate the MOD09A1 and the MPF observations before the DNN training. For each 8-day composite of MOD09A1, there are 40 tiles to cover the entire Arctic. We processed all the tiles into the mosaic and reprojected them to a GeoTIFF on the $500 \mathrm{~m}$ polar stereographic grid. Each spectral band (bands 1-7) is stored as a separate GeoTIFF file. The surface reflectance of MOD09A1 was obtained from the file which covers the date of the MPF observations, i.e., corresponding to the NSIDC MPF on 4 July 2000, the surface reflectance was obtained from the MOD09A1 with the date spanning from 3 to 10 July 2000, therefore it covers the MPF observation date. Before we processed the observed MPF, the MPF relative to ice-covered area was transformed to the MPF relative to the grid using the observed SIC. We located the MODIS grid that the observation falls in based on the recorded latitude, longitude, and date of observation. Then we calculated the averaged observed MPFs in each MODIS grid (note: MODIS grid in the same location but on a different date is regarded as a different grid). The averages of the observed MPFs corresponding to the MODIS grids were used in the DNN training. We evaluated the variance of the observed MPFs in $500 \mathrm{~m}$ grid. The results show that the observed MPFs in the central Arctic have small variance (most grids have the standard deviations within 5\%), while the observed MPF in the ice edges have relatively larger variance (some grids have standard deviations above $8 \%$ ). The average of these grid-based standard deviations is $7.71 \pm 6.77$.

Second, we built the DNN using the above processed data. The structure of the DNN is shown in Figure 2. The input in the DNN training is the processed spectral reflectance of the seven bands (bands 1-7) from MOD09A1 on the $500 \mathrm{~m}$ polar stereographic grid. The targets (output) are the observations from eight sources (NSIDC, PRIC-Lei, NPI, TransArc, HOTRAX, DLUT, IceWatch, JOIS) mentioned in Section 2.2. The first target data is the processed observed MPF relative to the grid. The second target data is the processed SIC. In the DNN training, we only considered the grids that meet the following conditions: (i) the surface reflectance in seven bands are all within the valid range; (ii) the observed MPF is above 0 and below $100 \%$; (iii) the observed MPF relative to the grid is smaller than the observed SIC (with MPF considered). In the DNN training, 25, 35, and 45 neurons were used in the first, second, and third hidden layer, respectively. The DNN randomly selects $80 \%, 10 \%$, and $10 \%$ of the data as the training, validation, and test dataset. The three datasets have no overlap. The training dataset was used to build the relationship between the input and the target. The validation dataset was used to tune the parameters to avoid overfitting and to validate if the network has learned some meaningful relationship from the training dataset. The test dataset was completely independent data that was used to evaluate the performance of the network. 


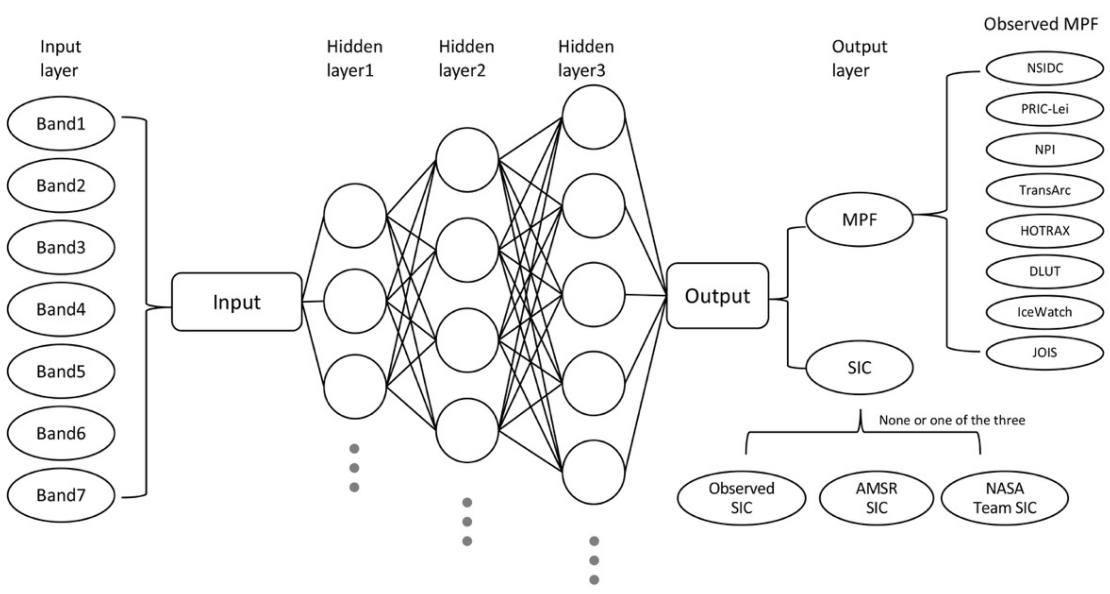

Figure 2. The structure of the DNN for the MPF retrieval.

To evaluate the impacts of different SIC target data on the MPF retrieval, the DNN was built by the four combinations (Table 2). The training input (spectral reflectance from seven bands of MOD09A1) remained unchanged. Here we used the same training, validation, and test datasets for the four network combinations. The cost functions used in the four networks are all mean squared errors. The only difference among the four networks is the SIC target (output) data.

- $\quad$ DNN_MPF (no SIC) is the DNN trained only using the processed MPF from the observations in Section 2.2 as the target data. The DNN_MPF (no SIC) does not include SIC as the target.

- DNN_MPF+ ObsSIC is the DNN trained by adding the processed SIC from the observations in Section 2.2 as the second target. The observed MPF and SIC are from the same source.

- DNN_MPF+AMSRSIC is the DNN trained by adding the SIC derived from the Advanced Microwave Scanning Radiometer-Earth Observing System and Advanced Microwave Scanning Radiometer 2 (referred to as AMSR SIC [64]) as the second target. The AMSR SIC is developed by the University of Bremen using the ARTIST Sea Ice algorithm. In the DNN training, the AMSR SIC was resampled from $6.25 \mathrm{~km}$ to the $500 \mathrm{~m}$ polar stereographic grid and then extracted based on the latitude and longitude of the corresponding MPF observation. The SIC data can be found at https://seaice.uni-bremen.de/sea-ice-concentration.

- DNN_MPF+NASASIC is the DNN trained by adding the SIC derived from the Nimbus-7 SMMR and DMSP SSM/I-SSMIS Passive Microwave Data based on a NASA Team algorithm (referred to as NASA Team SIC [62]) as the second target. In the DNN training, the NASA Team SIC is resampled from $25 \mathrm{~km}$ to the $500 \mathrm{~m}$ polar stereographic grid and then extracted based on the latitude and longitude of the corresponding MPF observation. The SIC data can be found at https://nsidc.org/data/nsidc-0051.

Table 2. Details of the target and output for the network.

\begin{tabular}{cccc}
\hline Network & Training Input & Training & Training Target (Output) \\
\hline DNN_MPF (no SIC) & & Observed MPF & MPF (no SIC) \\
DNN_MPF+ObsSIC & MODo9A1 surface & Observed SIC & \\
& Observed MPF and & MPF + SIC \\
DNN_MPF+AMSRSIC & (Bands 1-7) & AMSR SIC & \\
DNN_MPF+NASASIC & & Observed MPF and & \\
& & NASA Team SIC & \\
\hline
\end{tabular}

Third, we ran the DNN 100 times with random weights and biases assigned initially for the neurons in the four network combinations, which generated four groups of 100 networks. Table 3 
shows the mean correlation coefficients and RMSE with standard deviations (estimated from each group of 100 networks) against the observations in training, validation, test, and total datasets for the four network combinations. The results show that the MPF retrievals from the different datasets have comparable R (range from 0.60 to 0.67 ) and RMSE (range from 0.082 to 0.089 ). This suggests the network is not overfitted. The MPF derived by DNN_MPF+ObsSIC shows relatively stronger correlations and lower RMSE. Figure 3 shows the performance of the 100 networks in total dataset using DNN_MPF+ObsSIC. The correlation coefficients between the observations and the MPF retrieved from the networks range from 0.57 to 0.67 and the RMSE range from 0.082 to 0.091 . This suggests that the relationship identified by the network is sensitive to initially assigned weight and bias. To obtain a robust network, we removed the 20 networks with 10 highest and 10 lowest correlation coefficients, and selected the 80 networks which correlation coefficients range within 10-90 percentile of the 100 networks. We applied the ensemble averaging to the selected networks (ensemble-based DNN). The ensemble average is the averaged MPF of the MPFs derived from the selected 80 networks. We used the ensemble average as the final output. As shown in Figure 3, the retrieved MPF from the ensemble average is in a good agreement with the MPF measurements. The correlation coefficient is 0.65 and the RMSE is 0.083 , which are both better than most of the 100 networks. The ensemble averaging can smooth the retrievals and reduce the effects of singular values. It is widely used in numerical model studies and has been demonstrated that it has better performance than a single simulation.

Table 3. Mean correlation coefficients and RMSE against the observations in training, validation, test, and total datasets for the four network combinations.

\begin{tabular}{ccccc}
\hline R and RMSE & $\begin{array}{c}\text { DNN_MPF } \\
\text { (No SIC) }\end{array}$ & $\begin{array}{c}\text { DNN_MPF } \\
\text { +ObsSIC }\end{array}$ & $\begin{array}{c}\text { DNN_MPF } \\
\text { +AMSRSIC }\end{array}$ & $\begin{array}{c}\text { DNN_MPF } \\
\text { +NASASIC }\end{array}$ \\
\hline Training R & $0.67 \pm 0.02$ & $0.66 \pm 0.02$ & $0.65 \pm 0.03$ & $0.65 \pm 0.02$ \\
Validation R & $0.61 \pm 0.03$ & $0.63 \pm 0.03$ & $0.60 \pm 0.03$ & $0.61 \pm 0.03$ \\
Test R & $0.60 \pm 0.03$ & $0.63 \pm 0.03$ & $0.60 \pm 0.03$ & $0.61 \pm 0.03$ \\
Total R & $0.65 \pm 0.02$ & $0.65 \pm 0.02$ & $0.64 \pm 0.02$ & $0.65 \pm 0.02$ \\
Training RMSE & $0.083 \pm 0.002$ & $0.082 \pm 0.002$ & $0.084 \pm 0.002$ & $0.085 \pm 0.002$ \\
Validation RMSE & $0.088 \pm 0.004$ & $0.083 \pm 0.003$ & $0.089 \pm 0.003$ & $0.088 \pm 0.004$ \\
Test RMSE & $0.089 \pm 0.003$ & $0.084 \pm 0.004$ & $0.089 \pm 0.004$ & $0.089 \pm 0.003$ \\
Total RMSE & $0.084 \pm 0.002$ & $0.083 \pm 0.002$ & $0.085 \pm 0.002$ & $0.086 \pm 0.002$ \\
\hline
\end{tabular}
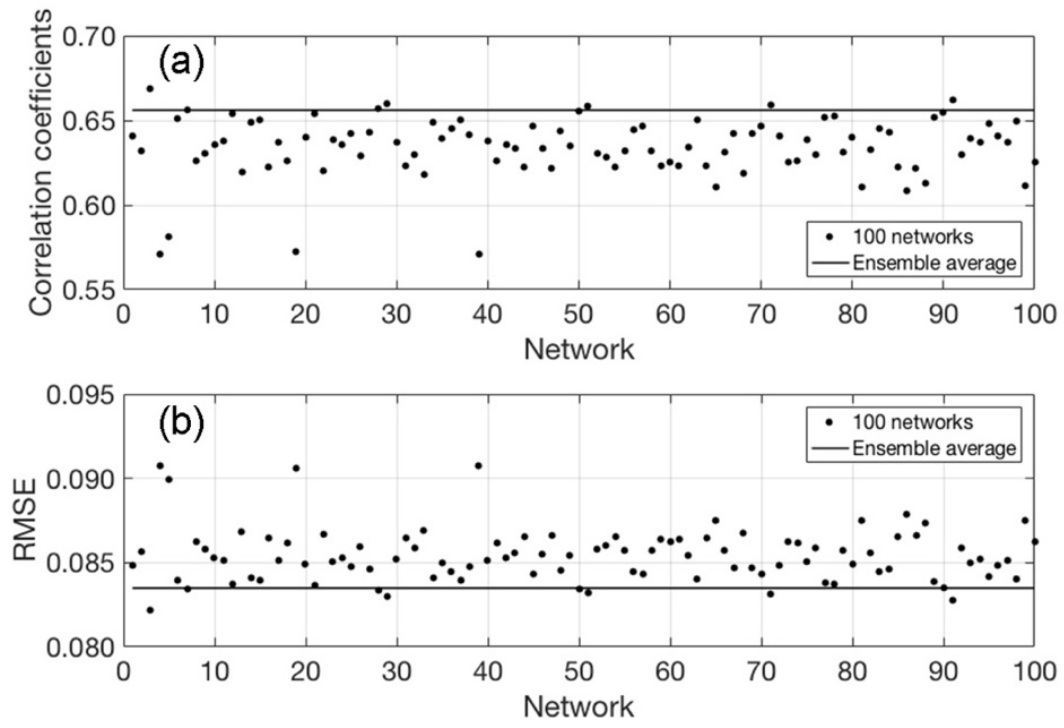

Figure 3. Correlation coefficients (a) and RMSE (b) between the observed MPF and the retrieved MPF from 100 networks and the ensemble average of the selected networks. 


\subsubsection{Retrieval of the Final MPF Dataset}

For the final MPF dataset, we aimed to develop the dataset on the $12.5 \mathrm{~km}$ grid to match the resolution of the previous MPF datasets $[35,36]$ and also to make it comparable with most SIC data and the independent validation data. We resampled the aforementioned MOD09A1 GeoTIFF files of seven bands from the $500 \mathrm{~m}$ to $12.5 \mathrm{~km}$ polar stereographic grid using the mean value of a $25 \times 25$ size window. We then applied the ensemble-based DNN to derive the final MPF dataset from 2000 to 2019. The input is the surface reflectance of seven bands (bands 1-7) from MOD09A1 on the $12.5 \mathrm{~km}$ polar stereographic grid. The output trained by the ensemble-based DNN is the MPF relative to the grid on the $12.5 \mathrm{~km}$ polar stereographic grid. This is also the case for SIC for DNN_MPF+ObsSIC, DNN_MPF+AMSRSIC, DNN_MPF+NASASIC (Table 2).

\section{Results}

\subsection{Evaluation}

In this study, we used all seven spectral bands from MOD09A1 to retrieve the MPF in comparison with that of Rösel et al. [33,35] which only used three MOD09A1 bands. To evaluate the importance of each MODIS band, we calculated the relative contribution of each band on the MPF retrieval using "connection weights" proposed by Olden and Jackson [65]. The "connection weights" calculates the product of the raw input-hidden and hidden-output connection weights between each input and output neuron and sums the products across all hidden neurons. The results show the largest contribution is from MOD09A1 band 4 (21\%). Although the contributions from band 1 to band 4 are higher than that from band 5 to band 7, each MOD09A1 band shows considerable contribution (above 10\%) in the MPF retrieval (Figure 4). Additionally, we used the "increased RMSE" method proposed by Gevrey et al. [66] to further evaluate the variable importance. The importance was based on the changes in the RMSE by sequentially setting input variables to their mean value. The results show the similar importance to that calculated by "connection weights". These suggest that using all seven spectral bands benefits the MPF retrieval.

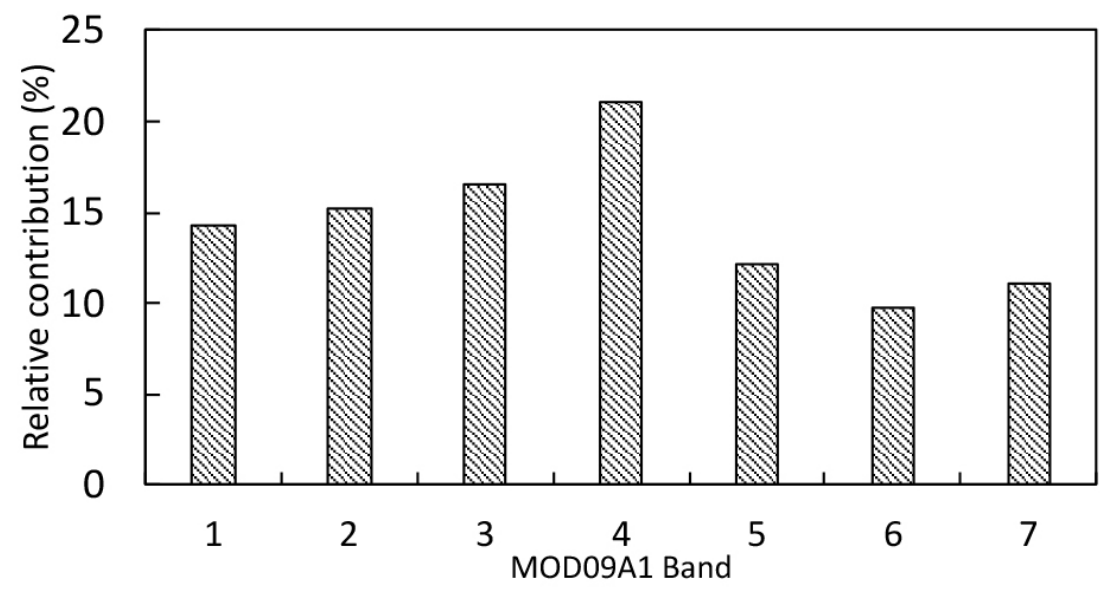

Figure 4. Relative contribution of each MOD09A1 band in MPF retrieval.

To evaluate the impact of adding SIC as the target data on the MPF retrieval, we calculated the spatial correlation coefficient and RMSE of the MPFs from the three networks containing SIC against the MPF from DNN_MPF (no SIC) in each year during 2000-2019. The results show that the average spatial correlation coefficient is $\approx 0.99$ and the RMSE is $\approx 0.01$. This suggests that the MPF from the networks which contain SIC as the target data are generally consistent with that from DNN_MPF (no SIC). We further examined the percentage of grid cell with MPF greater than NASA Team SIC (considered as bad retrieval) from the four networks (Table 4). The results suggest a decreasing trend for the MPF bad retrievals during 2000-2019. This is related to the reduced total grid cells in the 
study period. The bad retrievals mostly appear in the ice edges. As the ice edges gradually retreated, the bad retrievals also decrease. Additionally, the MPF in Table 4 is compared with the NASA Team SIC, which is underestimated in summer due to ponds and may affect the estimation of bad retrievals. If we compare the MPF with the SIC retrieved by DNN_MPF+ObsSIC, these bad retrievals will be greatly reduced. As shown in Table 4, for DNN_MPF (no SIC), $0.09 \%$ of the grid cells have bad MPF retrieval when considering grids with SIC $>30 \%$. The percentage of the grids with MPF larger than NASA Team SIC does not change much for the other three networks which contain SIC. This suggests adding SIC as the target has small effects on the MPF retrieval in our method, but adding observed SIC (DNN_MPF+ObsSIC) can help to reduce the amounts of bad retrievals $(0.05 \%)$. In this study, we used the retrieval from DNN_MPF+ObsSIC. The bad retrievals were removed in the analyses.

Table 4. The percentage of the grid cell (bad retrieval) with MPF relative to grid greater than NASA Team SIC.

\begin{tabular}{cccccc}
\hline & \multicolumn{5}{c}{ MPF $>$ NASA Team SIC (SIC > 30\%) } \\
Year & DNN_MPF (No SIC) & $\begin{array}{c}\text { DNN_MPF+ } \\
\text { ObsSIC }\end{array}$ & $\begin{array}{c}\text { DNN_MPF+ } \\
\text { DMSRSIC }\end{array}$ & $\begin{array}{c}\text { DNN_MPF+ } \\
\text { NASASIC }\end{array}$ & Total Grid Cells \\
\hline 2000 & 0.09 & 0.08 & 0.27 & 0.17 & 49,127 \\
2001 & 0.12 & 0.03 & 0.22 & 0.13 & 45,253 \\
2002 & 0.13 & 0.04 & 0.21 & 0.10 & 47,358 \\
2003 & 0.12 & 0.07 & 0.18 & 0.13 & 48,097 \\
2004 & 0.10 & 0.04 & 0.20 & 0.12 & 47,545 \\
2005 & 0.14 & 0.06 & 0.22 & 0.12 & 45,805 \\
2006 & 0.14 & 0.06 & 0.25 & 0.12 & 45,281 \\
2007 & 0.08 & 0.05 & 0.20 & 0.11 & 42,082 \\
2008 & 0.09 & 0.09 & 0.16 & 0.11 & 43,445 \\
2009 & 0.08 & 0.09 & 0.22 & 0.13 & 44,937 \\
2010 & 0.09 & 0.04 & 0.22 & 0.12 & 42,775 \\
2011 & 0.07 & 0.05 & 0.19 & 0.10 & 41,503 \\
2012 & 0.09 & 0.03 & 0.11 & 0.09 & 39,476 \\
2013 & 0.06 & 0.02 & 0.13 & 0.08 & 43,269 \\
2014 & 0.07 & 0.05 & 0.17 & 0.09 & 43,127 \\
2015 & 0.03 & 0.01 & 0.11 & 0.07 & 41,843 \\
2016 & 0.09 & 0.02 & 0.16 & 0.08 & 40,403 \\
2017 & 0.04 & 0.05 & 0.11 & 0.08 & 41,081 \\
2018 & 0.06 & 0.05 & 0.10 & 0.08 & 40,231 \\
2019 & 0.04 & 0.03 & 0.09 & 0.07 & 39,867 \\
Average & 0.09 & 0.05 & 0.18 & 0.11 & 43,625 \\
\hline
\end{tabular}

In this study, we used the MPF on both the $500 \mathrm{~m}$ and $12.5 \mathrm{~km}$ polar stereographic grid to validate our retrieval. Figure 5 shows the validation against the observations on the $500 \mathrm{~m}$ polar stereographic grid. The validation data used here are the total dataset (combination of training, validation, and test data). In general, the retrieved MPF shows best performance with the NSIDC observations $(r=0.70$, RMSE $=0.066$ in Figure 5a). This is not only due to the relatively larger number of observations from NSIDC used in the DNN training, but also the same resolution of NSIDC observations with MODIS data. For the validations against other observations, the RMSEs, except for IceWatch and JOIS, are generally within 0.1 which is proposed as an important factor to evaluate the data accuracy in Wright and Polashenski [34]. We further evaluated the correlations and RMSE on the training, validation, and test dataset for each observation (Table S1). The results show that the R and RMSE in different datasets are comparable. This suggests the network has been trained but not overfitted. In addition, the root mean square (RMS) of the observed MPF in the sub-figures are all larger than the RMSE (Table S2). 

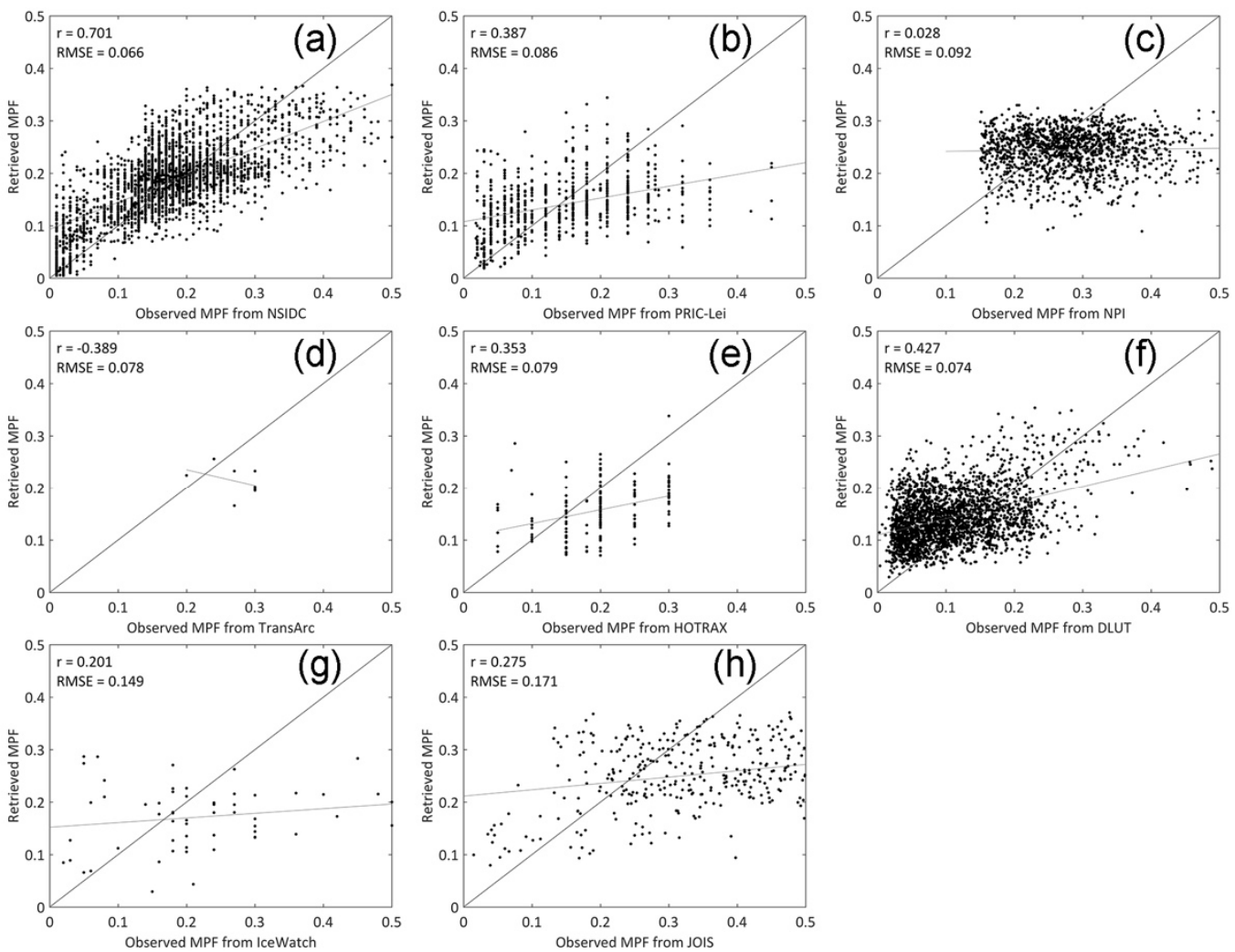

Figure 5. Validation of the retrieved MPF against the observed MPF on the $500 \mathrm{~m}$ polar stereographic grid. (a) NSIDC, (b) PRIC-Lei, (c) NPI, (d) TransArc, (e) HOTRAX, (f) DLUT, (g) IceWatch, (h) JOIS.

Figure 6 provides map-based cases of the observed MPF from multiple sources overlaid on our retrieved MPF. It appears that the retrieved MPF has reasonable agreement with the observations. We note that the large difference is usually found for the observed MPF above $35 \%$. This is partly due to the observed MPF focused on small areas (within $1 \times 1 \mathrm{~km}$ ), which has large possibility of MPF above $35 \%$. However, for the areas of $12.5 \times 12.5 \mathrm{~km}$, the possibility of such high MPF is reduced.
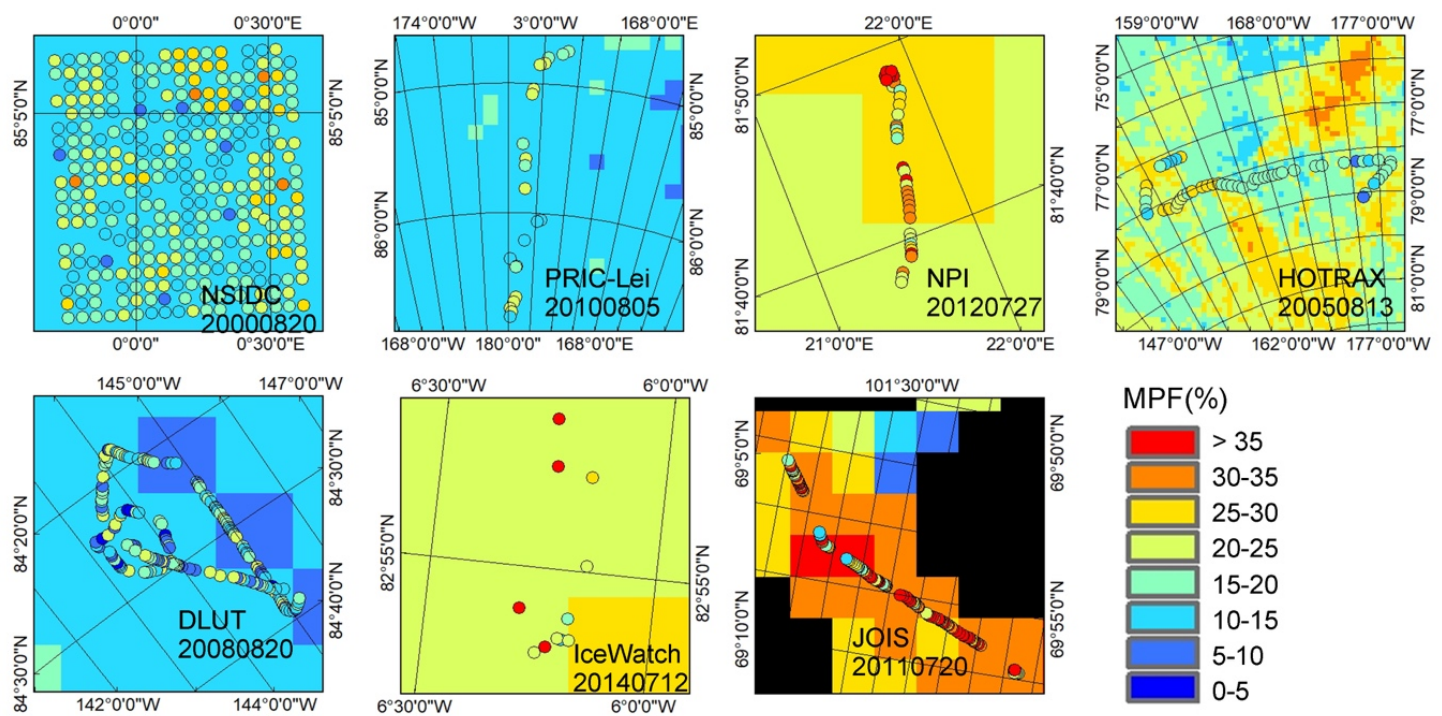

Figure 6. Map-based cases of the observed MPF from multiple sources overlaid on the retrieved MPF.

For detailed validation, we examined our retrieved MPF (DNN_MPF) and the MPF version 2 (UH_MPFv2) developed by Rösel et al. [35] against the observations on $12.5 \mathrm{~km}$ polar stereographic 
grid (Figure 7). We only used the observations where DNN_MPF and UH_MPFv2 are both within the valid ranges. The two MPFs were both retrieved from the MOD09A1 on the $12.5 \mathrm{~km}$ polar stereographic grid. The validation data used here are the total dataset. Some validation of the UH_MPFv2 is missing due to the invalid UH_MPFv2 or data gap after 2011. The validations suggest that the DNN_MPF shows better agreement with the observations than UH_MPFv2 (Figure 7). The correlation coefficients of DNN_MPF are all higher than that of UH_MPFv2, i.e., the validation against PRIC-Lei $(r=0.54$ vs. $r=0.31$ in Figure $7 b)$, HOTRAX ( $r=0.53$ vs. $r=0.48$ in Figure $7 e)$, DLUT $(r=0.61$ vs. $r=-0.20$ in Figure $7 \mathrm{f}$ ), and JOIS ( $\mathrm{r}=0.71$ vs. $\mathrm{r}=0.65$ in Figure $7 \mathrm{~h}$ ). The DNN_MPF shows relatively better performance with the observations from NSIDC $(r=0.80)$, DLUT, and JOIS. However, the validations against the TransArc observations for the two MPF data are both not good. For the $12.5 \mathrm{~km}$ retrieval, the RMSE of DNN_ MPF is generally within 0.1, except for IceWatch. The RMS of each observations are also larger than the RMSE (Table S2) as that in the $500 \mathrm{~m}$ grid. The results suggest that the validation on $12.5 \mathrm{~km}$ grid is even better than that of the $500 \mathrm{~m}$ grid. This can be partly explained by the large variabilities of MPFs in small areas (within $1 \times 1 \mathrm{~km}$ ), while these variabilities can be smoothed in large areas $(12.5 \times 12.5 \mathrm{~km})$.
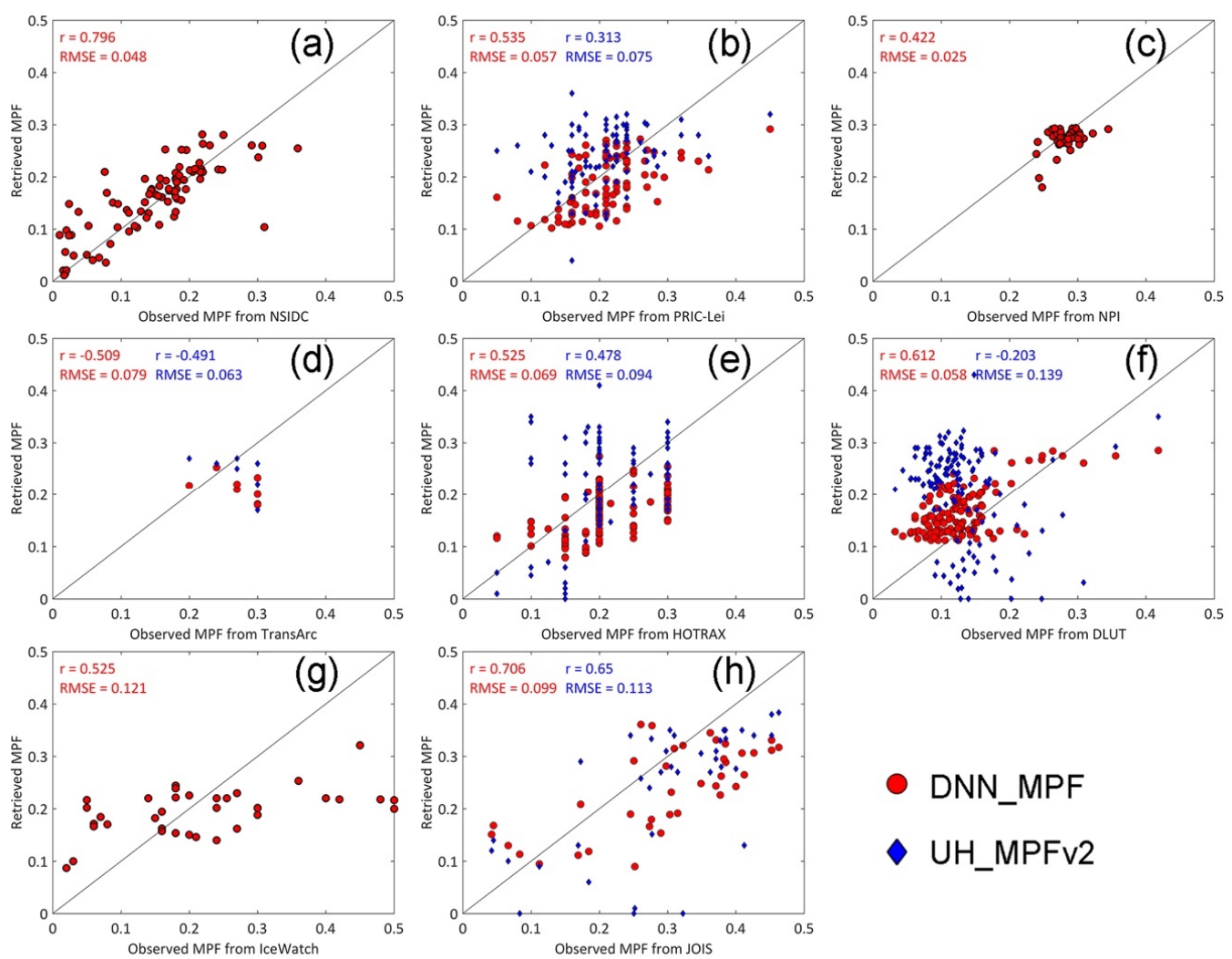

Figure 7. Validation of the DNN_MPF and UH_MPFv2 against the observed MPF on the $12.5 \mathrm{~km}$ polar stereographic grid. (a) NSIDC, (b) PRIC-Lei, (c) NPI, (d) TransArc, (e) HOTRAX, (f) DLUT, (g) IceWatch, (h) JOIS.

We note that the above observations have been used as samples in the DNN training. To further evaluate our data quality, we used the observations from MEDEA and WorldView as the independent validations (Figure 8c,d). The observations from IceWatch and TransArc with visibility of $10 \mathrm{~km}$ or above are also used as independent validations (Figure $8 \mathrm{a}, \mathrm{b}$ ). Note: these observations were not used in the DNN training. The results suggest that the retrieved MPFs have better agreement with the satellite-based observations (MEDEA and WorldView) than the manual observations (TransArc and IceWatch), which have larger uncertainties in MPF measurements. The original satellite images with meter to decimeter resolution used in MEDEA and WorldView observations can capture the 
detailed ice surface features, which help improve the classification accuracy of surface types $[8,45]$. Previous studies showed the overall classifier accuracy of MEDEA observation was as high as 96-99\% during May to August [8], and the accuracy of the type determination in WorldView observation is approximately 96\% [45]. The MEDEA and WorldView observations have been used as the validation data in many previous studies [34,50,67-70]. These suggest that the satellite-based observations from MEDEA and WorldView have sufficient accuracy to be used for the independent validation. The DNN_MPF and UH_MPFv2 show good performance ( $r=0.80$ vs. $r=0.75)$ when validating with the MEDEA observations (Figure 8c). The correlation coefficients of DNN_MPF against WorldView observations is 0.61 and the RMSE is 0.08 (Figure $8 \mathrm{~d}$ ). The RMSE (0.08) is much smaller than that of UH_MPFv2, which is 0.18 calculated by Wright and Polashenski [34]. In this study, we did not use the fixed spectral reflectance of each surface type (i.e., bare ice, snow cover ice, melt pond, and open water) to build the relationship. Instead, we used the observed MPF from multiple sources to directly train the DNN. The advantage of our method is that it avoids large uncertainties of spatially and temporally varying reflectance associated with surface species, which can result in large uncertainties for the retrieval. The "spectral unmixing" that used the constant reflectance in Rösel et al. [33,35] has been proposed as a problem in MPF retrieval by Wright and Polashenski [34]. Our retrieval directly based on the DNN might help to solve this issue.
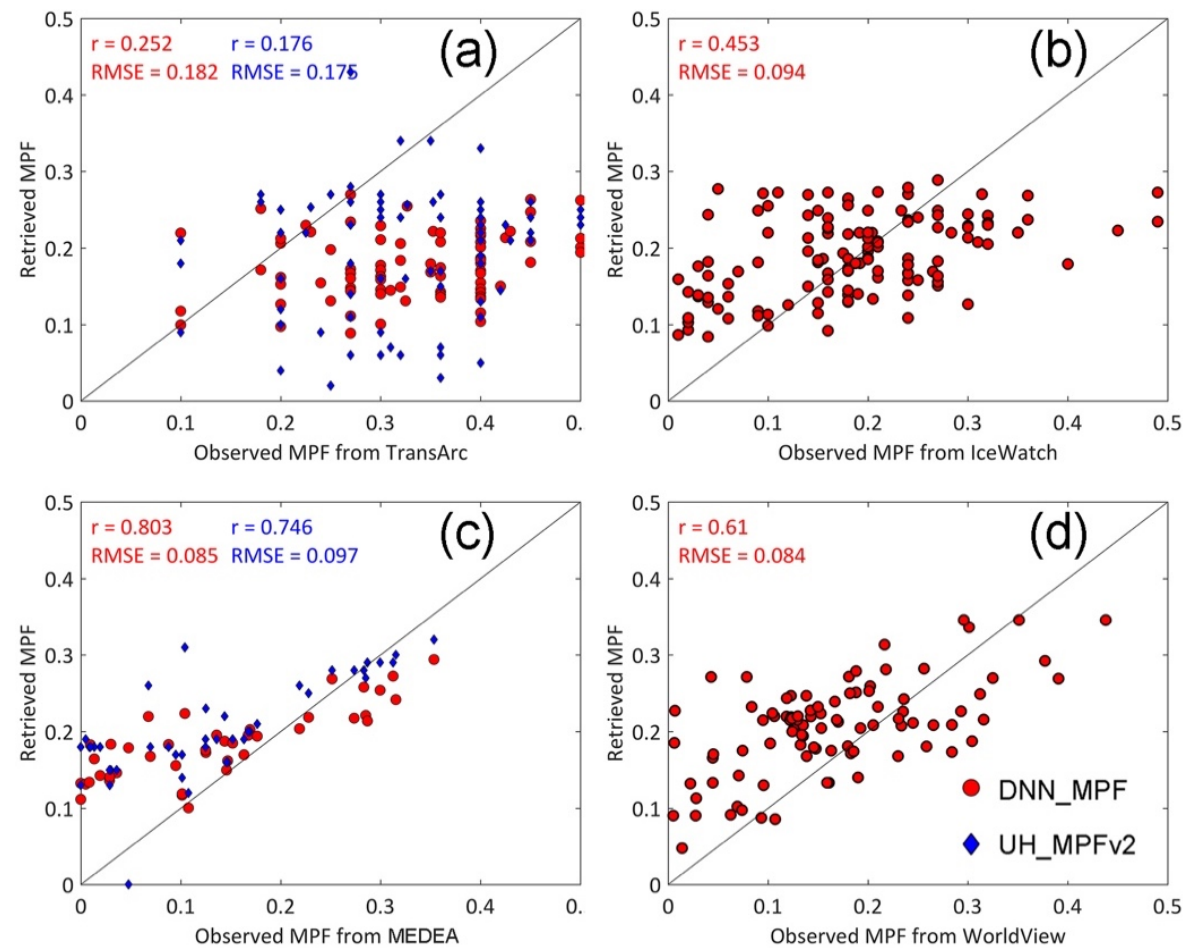

Figure 8. Independent validation of the DNN_MPF and UH_MPFv2 against the observed MPF on the $12.5 \mathrm{~km}$ polar stereographic grid. (a) TransArc, (b) IceWatch, (c) MEDEA, (d) WorldView.

\subsection{Uncertainties}

Here we examined the accuracy of the DNN_MPF in each month by calculating the probability density distribution (PDF) of the bias (DNN_MPF minus observed MPF) in $500 \mathrm{~m}$ grid. As shown in Figure 9, the PDF is normal distribution and most of the bias are within in the range of $-0.1-0.1$. For each individual month (Figure 10), the DNN_MPF in June shows the best performance. The retrieval in July and August has similar distribution, even though the DNN_MPF in July seems slightly toward negative side. The retrieval in September shows the similar PDF distribution, but it has relatively higher probability with large bias. This is due to the fewer observations (172 observations) in September used in the network training. 


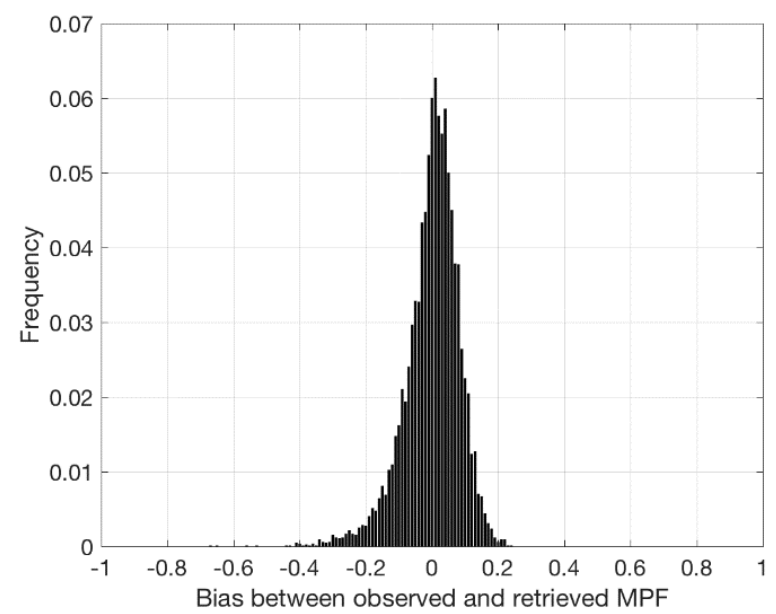

Figure 9. Probability density distribution of the bias between the DNN_MPF and the observed MPF in the $500 \mathrm{~m}$ grid for the entire observation period.
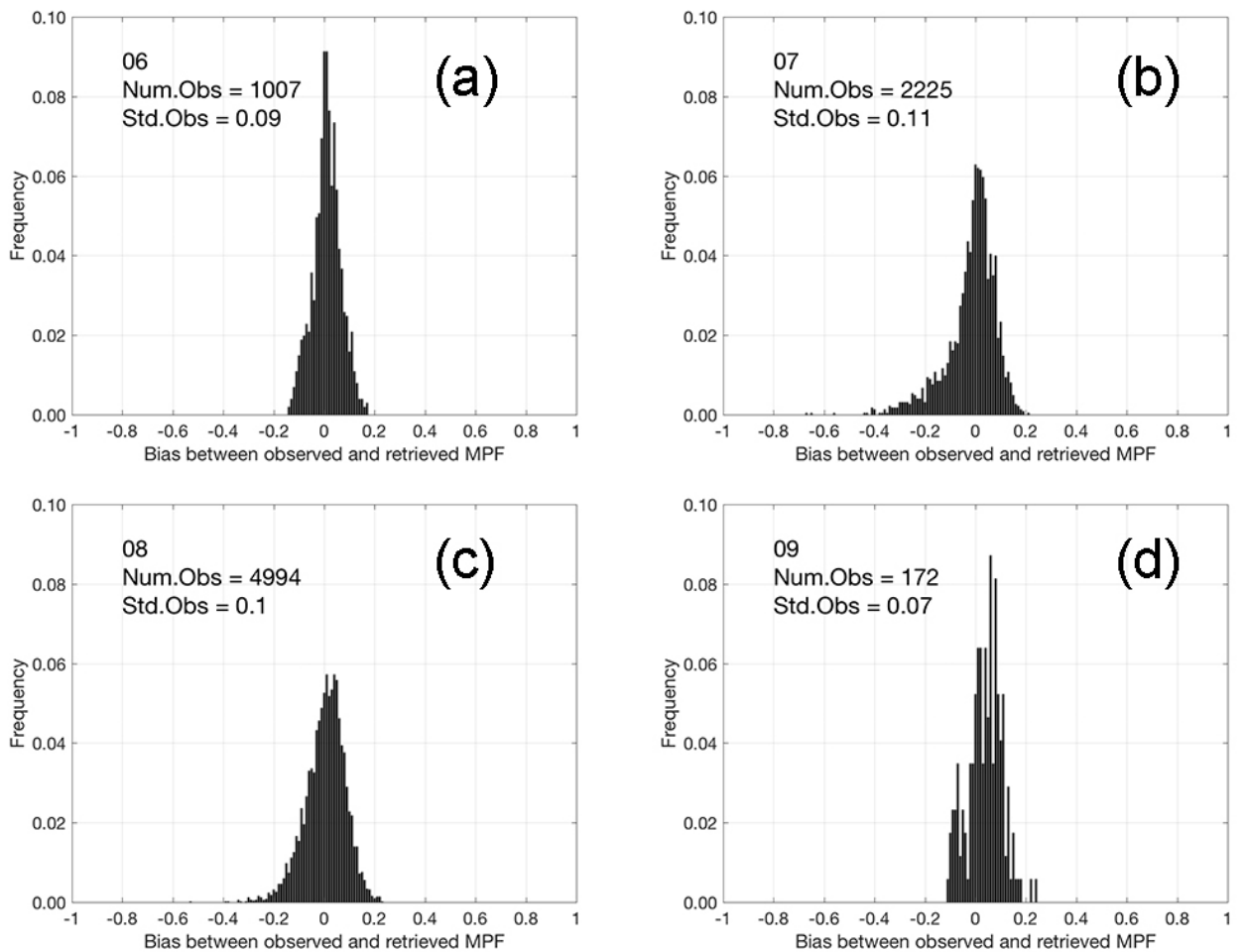

Figure 10. Probability density distribution of the bias between the DNN_MPF and the observed MPF in the $500 \mathrm{~m}$ grid for each month. (a) June, (b) July, (c) August, (d) September.

The uncertainties are further estimated by the standard deviations among the outputs of networks within 10-90 percentile of the 100 networks described in Section 2.4.1. Here we calculated the standard deviation in each $12.5 \mathrm{~km}$ grid from May to September during 2000-2019. The uncertainties in Table 5 were estimated by the average of the grid-based standard deviation on each date during 2000-2019. The results show that the magnitude of the uncertainty of our MPF retrieval varies slightly from May to August, with an average of $1.9 \%$. The uncertainty of SIC is slightly larger than that of the MPF, within 5-6\% in May and then decreases during June to September. The small uncertainties suggest that our retrieval using the ensemble-based networks is robust. Figure 11 shows the spatial distribution of the grid-based standard deviations of the DNN_MPF averaged for the period of May to September during 2000-2019. The uncertainties of MPF are generally within 5\% in much of the Arctic Ocean 
during the entire melting season. In May, the MPF uncertainties in the central Arctic are about 1-3\% larger than other months, especially for that in the first 8-day period. In June and July, the uncertainties decrease and are mostly within 3\%. In August, the uncertainties increase by about $2 \%$ in most of the Arctic. The DNN_MPF shows generally larger uncertainties in the ice edge zone from June to August and in the Canadian Archipelago from May to June. We further check the spatial distribution of the uncertainties of the DNN_MPF in 2001 (the year with the largest sea ice extent in September) and 2012 (the year with the smallest sea ice extent in September). Consistent with Figure 11, the uncertainties of MPF in the two years are within 5\% in most areas. The uncertainties of DNN_MPF are about 2-3\% larger during June to July in 2001 than that in 2012.

Table 5. Average of the uncertainties (\%) for grid-based DNN_MPF and DNN_SIC from May to September during 2000-2019.

\begin{tabular}{ccc}
\hline Date & DNN_MPF & DNN_SIC \\
\hline $05 / 09$ & 2.61 & 5.96 \\
$05 / 17$ & 2.45 & 5.83 \\
$05 / 25$ & 2.27 & 5.49 \\
$06 / 02$ & 2.00 & 4.76 \\
$06 / 10$ & 1.87 & 3.99 \\
$06 / 18$ & 1.77 & 3.54 \\
$06 / 26$ & 1.63 & 3.09 \\
$07 / 04$ & 1.45 & 2.67 \\
$07 / 12$ & 1.37 & 2.56 \\
$07 / 20$ & 1.39 & 2.61 \\
$07 / 28$ & 1.47 & 2.82 \\
$08 / 05$ & 1.57 & 3.11 \\
$08 / 13$ & 1.71 & 3.39 \\
$08 / 21$ & 1.81 & 3.63 \\
$08 / 29$ & 2.00 & 4.05 \\
$09 / 06$ & 2.23 & 4.43 \\
Average & 1.85 & 3.87 \\
\hline
\end{tabular}

\subsection{Inter-Comparison}

In this study, we compare our MPF dataset with the UH_MPFv2 [35] and the MPF developed by Istomina et al. [36] (referred as UB_MPF). The UB_MPF consists of daily MPF retrieved from MERIS swath Level $1 \mathrm{~b}$ data using the MPD (Melt Pond Detector) retrieval [37]. To compare with DNN_MPF and UH_MPFv2, we calculated the 8-day averages of the UB_MPF corresponding to the date ranges of the MOD09A1 8-day composite. All the MPFs are the fraction relative to the $12.5 \mathrm{~km}$ polar stereographic grid.

Figures 12-14 show the averaged DNN_MPF, UH_MPFv2, and UB_MPF in the period of May to September from 2003 to 2011 (the overlapping period of the three datasets). The climatology of the three MPFs do not exceed $40 \%$ in most areas of the Arctic, except for the Canadian Archipelago in the UB_MPF. In May, the DNN_MPF and UH_MPFv2 have similar spatial pattern in much of the Arctic Ocean, but the UH_MPFv2 is relatively larger in the sea ice edge zone of the Barents Sea, Greenland Sea, and Hudson Bay. The UB_MPF is generally larger than the other two data in the central Arctic. In June, the DNN_MPF and UH_MPFv2 have comparable MPF in the ice edges (around $25 \%$ ), especially in the Baffin Bay, Kara Sea, and East Siberian Sea. The DNN_MPF is slightly smaller than the UH_MPFv2. The DNN_MPF and UH_MPFv2 both show apparent increase in the end of June. In the Arctic Basin, the UB_MPF tends to evolve early in the western Arctic dominated by the multi-year ice, while the DNN_MPF and UH_MPFv2 seem to evolve synchronously in the western and eastern region. The MPF of all three data increases quickly in the band of the Beaufort, Chukchi, and East Siberian Seas. The UB_MPF (above 35\%) covers most areas of the Canadian Archipelago in June, which is larger than the other two MPF data. In July, higher fractions (above $20 \%$ ) gradually 
extend to the central Arctic based on all three of the datasets. The DNN_MPF and the UH_MPFv2 have similar spatial pattern, but the large fraction (above 25\%) of DNN_MPF covers smaller areas than that of the UH_MPFv2. The DNN_MPF and UH_MPFv2 have similar amount of MPF in the eastern and western Arctic basin, although the UH_MPFv2 in the central Arctic is relatively larger. Different from the other two data, the UB_MPF has higher MPF in the western than the eastern regions. The DNN_MPF in the Canadian Archipelago shows apparently later increase than the other two MPFs and also has smaller fractions. In August, the MPF of the three datasets gradually decreases. The UH_MPFv2 is remarkably higher than the other two data. The UH_MPFv2 and UB_MPF, respectively, have the slowest and fastest decrease rate, while the decrease rate of the DNN_MPF is in between. During early to mid-August, the magnitude of the DNN_MPF varies slightly in most areas of the Arctic. That is also true for the UH_MPFv2, but the fractions of UH_MPFv2 is relatively larger. The large fraction (above 30\%) of UH_MPFv2 covers the ice edges even in late August. Different from the two MPFs which have similar fractions in the eastern and western central Arctic, the UB_MPF has larger fractions in the western regions. By the end of August, the DNN_MPF and UB_MPF are less than $20 \%$ in the Arctic basin, while the UH_MPFv2 still maintains at high fraction.

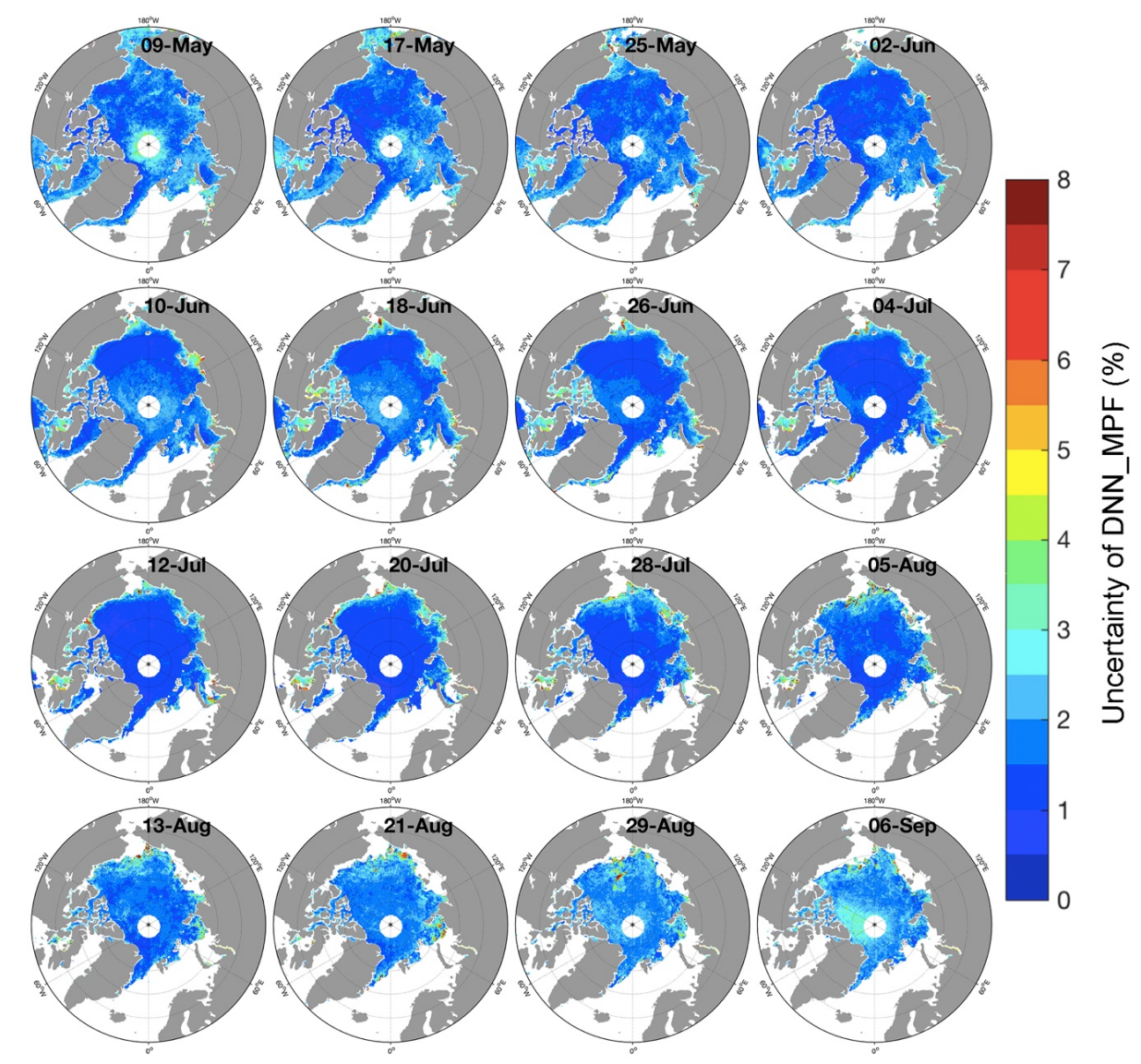

Figure 11. Uncertainties of the DNN_MPF from May to September during 2000-2019. 


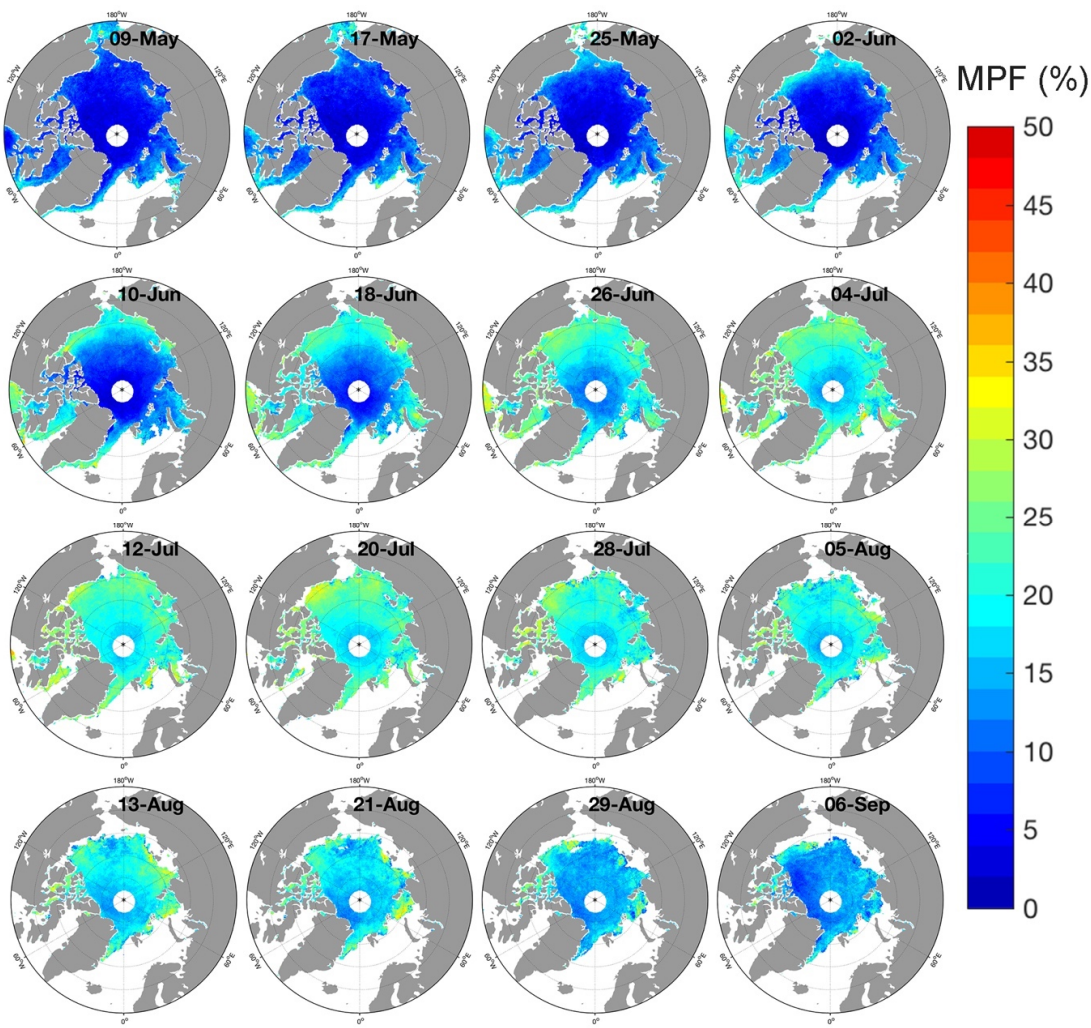

Figure 12. Averaged DNN_MPF for the period of May to September during 2003-2011.

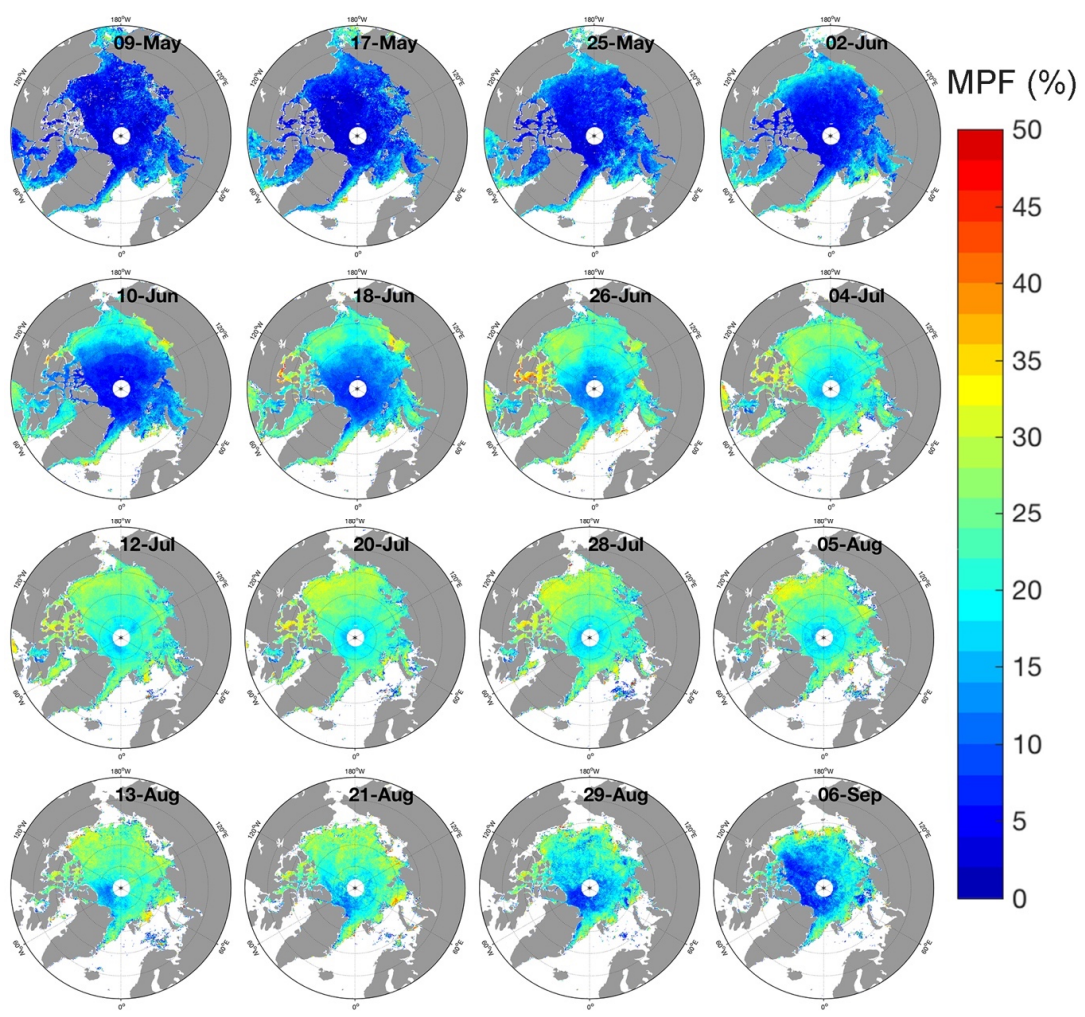

Figure 13. Same as Figure 12, except for the UH_MPFv2. 


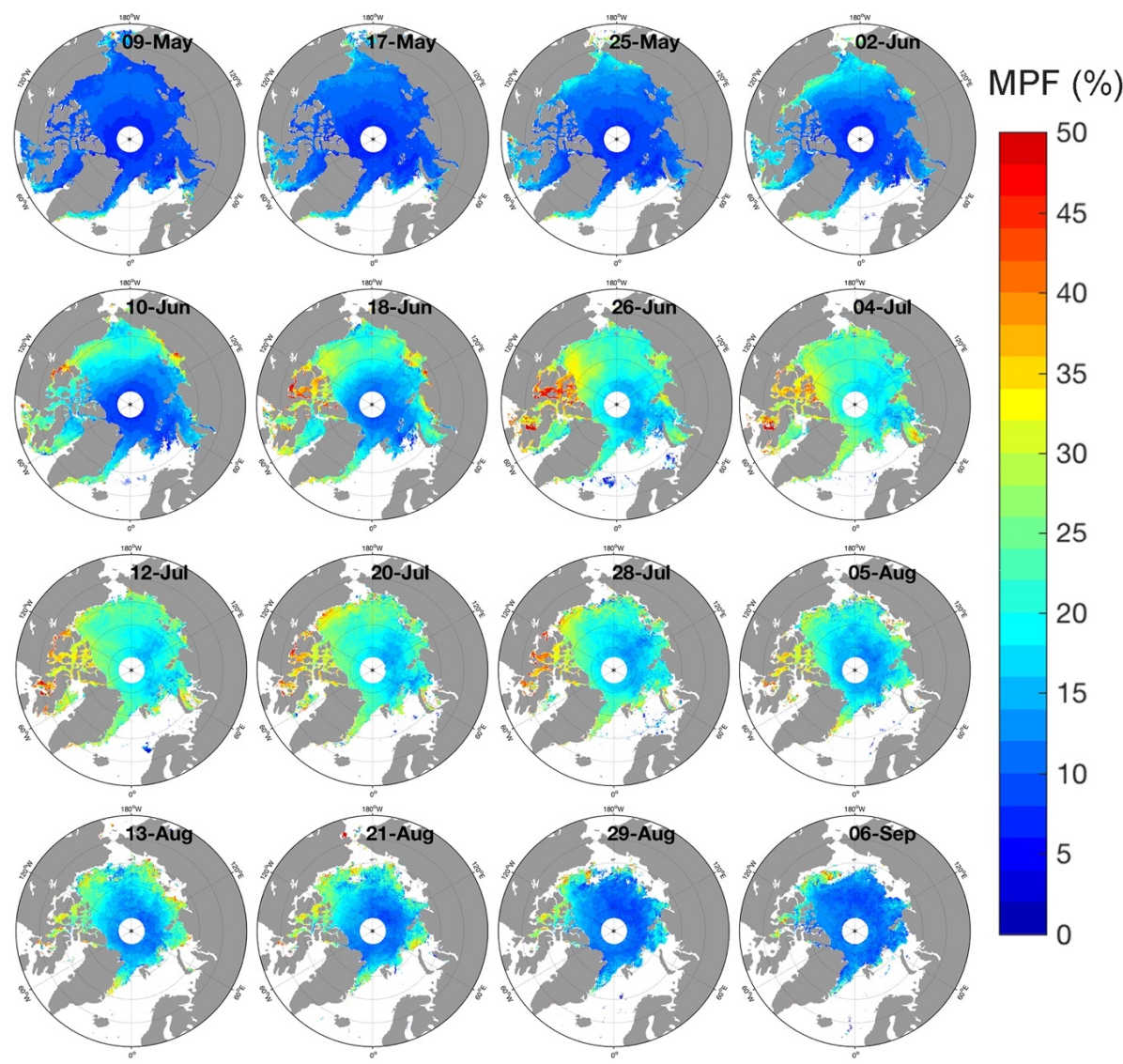

Figure 14. Same as Figure 12, except for the UB_MPF.

Figure 15 shows the time series of the three MPF data relative to the $12.5 \mathrm{~km}$ polar stereographic grid. Here we only consider the grids with SIC above 30\% and the region in the Arctic Circle (north of $\left.66.5^{\circ} \mathrm{N}\right)$. The three datasets have some amount of melt ponds in early May $(7.6 \%, 8.3 \%$, and $9.4 \%$ for DNN_MPF, UH_MPFv2, and UB_MPF), but our data has the smallest value. The relatively higher MPF for the three datasets in this period mainly appear on the ice edges. The DNN_MPF has a limited increase in May and the UH_MPFv2 and UB_MPF has an increase within $2 \%$. In June, the UB_MPF increases faster than the other two data and reach up to $20 \%$ in mid-late June, which is about $5 \%$ and $3 \%$ larger than the DNN_MPF and UH_MPFv2 at the same time. The DNN_MPF and UH_MPFv2 mainly evolves in late June. By the end of June, the fractions of the three data are 19\% (DNN_MPF), 21\% (UH_MPFv2), and 23\% (UB_MPF). The DNN_MPF and UH_MPFv2 both reach to the largest fraction $\approx 22 \%$ and $\approx 25 \%$ in late July, while the UB_MPF reach its maximum $\approx 23 \%$ in early July. This suggests the UB_MPF decreases about two 8-day periods earlier than the other two data. From late July to the end of melting season, the UH_MPFv2 always have higher MPF than the other two data. In August, the fractions of DNN_MPF and UB_MPF are close, although that of DNN_MPF is slightly larger. The UH_MPFv2 decline slower than the other two data and maintains at high fractions above $20 \%$ for a longer duration. The fraction of UH_MPFv2 is about $2-6 \%$ and $3-7 \%$ higher than the DNN_MPF and UB_MPF, respectively. The standard deviations of the three data are larger in June and August than other months. 


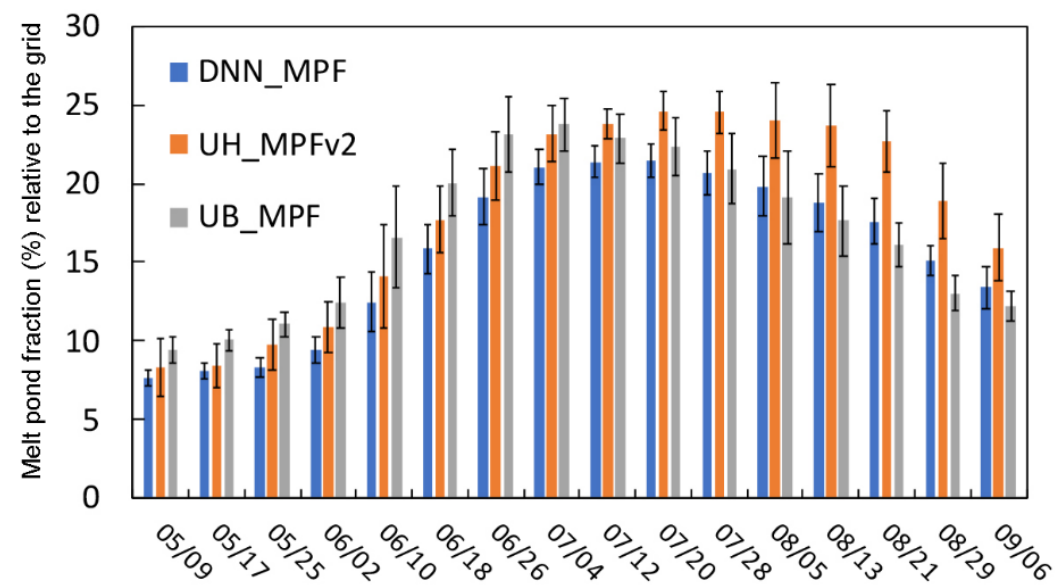

Figure 15. Evolution of the DNN_MPF, UH_MPF, and UB_MPF relative to the grid in the period of May to September during 2003-2011.

We further compared the evolution of the three MPFs relative to the grid during the melting season with the observed MPFs (Figure 16). We used the average of the observations from the aforementioned multiple sources to represent the observed MPF on the specific date range. We extracted the MPFs in the grids corresponding to those observations and calculated their averages to represent the retrieved MPFs. The results show that the DNN_MPF and the UH_MPFv2 are closer to the observed MPFs than the UB_MPF during the early melting season. The RMSE of the DNN_MPF against the observations is $\approx 1.4 \%$ in May, which is smaller than that of the other two MPFs. The DNN_MPF also shows better agreements with the observed MPFs during early to late June. The RMSE of DNN_MPF ranges from $1.2 \%$ to $8.4 \%$, which is smaller than that of UH_MPFv2 and UB_MPF. The three retrieved MPFs are relatively closer around mid-July than other periods and show good agreement with the observations during 10-15 July. The RMSE of the DNN_MPF (10.6\%) is smaller than the other two MPFs (RMSE $=14.5 \%$ for UH_MPFv2 and RMSE $=12.7 \%$ for UB_MPF) in July. In later melting season, the UH_MPFv2 and UB_MPF are, respectively, larger and smaller than the observed MPFs. The DNN_MPF in this period is generally between the UH_MPFv2 and UB_MPF and is also closer to the observed MPFs. The RMSE of the three MPFs against the observations all increase in August, and the values vary within the range of 8.5-12.2\% for DNN_MPF, 7.0-16.9\% for UH_MPFv2, and 7.0-19.1\% for UB_MPF, respectively.

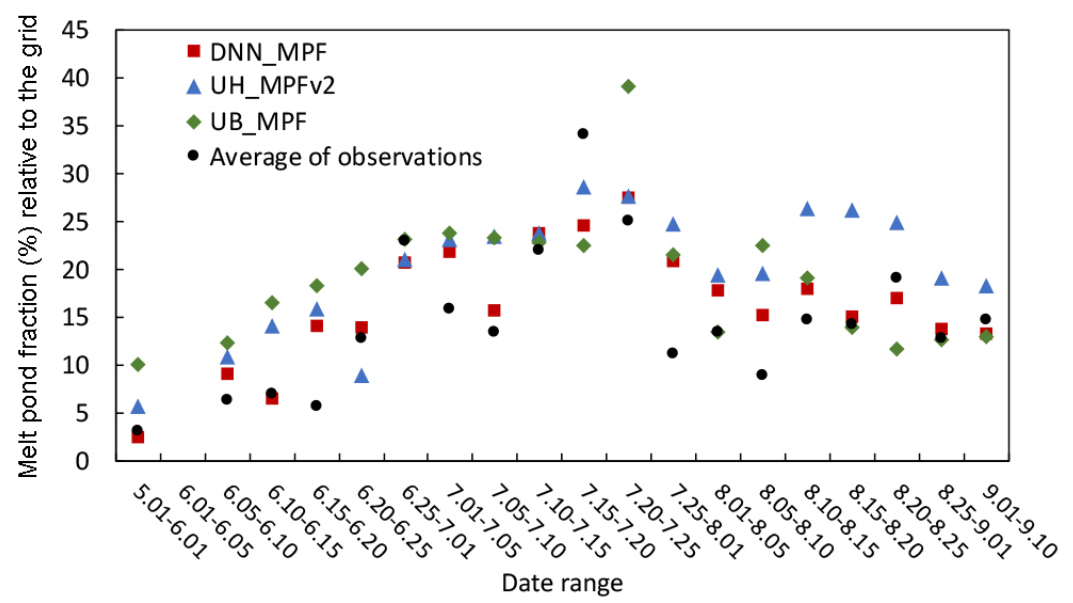

Figure 16. Comparison of the evolution of the three retrieved MPFs relative to the grid against the observations in the period of May to September during 2003-2011. 


\section{Discussion}

DNN is a powerful tool for data analysis and is particularly suitable for modeling complex relationships between variables. However, it suffers from the limitation of providing meaningful interpretations that can enhance understanding of underlying physical processes. This leads to a question whether the retrieval by DNN is better than simple approaches. Based on this, we conducted several experiments to evaluate the retrieval ability of DNN. First, we used the average of the observed MPF with 10 groups of random noises added (the noises have the similar standard deviations as the observed MPF) to examine whether the MPF derived from this simple approach (regarded as the estimated MPF) is better than our retrieval. The results show that the estimated MPF has little correlation with the observed MPF (Table 6). We further calculated the correlation coefficients by subtracting the estimated MPF from the observed MPF and DNN_MPF. The correlation coefficients did not decrease, which suggest the DNN has learned some complicated relationship (i.e., the variability of the MPF) more than just the mean MPF. Second, we used the linear regression based on the observed SIC to regress the MPF to evaluate if the DNN only calculates a simple fraction of the SIC. Compared to the DNN_MPF, the regressed MPF has weak or even negative correlations against most of the observations, i.e., -0.02 vs. 0.80 for NSIDC, 0.03 vs. 0.54 for PRIC-Lei, 0.11 vs. 0.42 for NPI, -0.55 vs. 0.53 for HOTRAX, -0.56 vs. 0.61 for DLUT, -0.49 vs. 0.71 for JOIS, -0.27 vs. 0.80 for MEDEA, 0.22 vs. 0.61 for WorldView. Additionally, the RMSE of the regressed MPF against the observations is also larger than that of the DNN_MPF. These suggest the DNN has captured a more complicated relationship than a simple fraction of SIC. Third, we used the multiple linear regression based on the surface reflectance of the seven MODIS bands (same as the input of DNN) to regress the MPF. The results show that the DNN_MPF is always better than the regressed MPF in both $500 \mathrm{~m}$ and $12.5 \mathrm{~km}$ grid as shown in Figure 17 (note: the TransArc only have eight observations for validation, and we think the negative correlations have no indication). The stronger correlations suggest the DNN has learned some complicated relationship, which cannot be obtained only from a simple method like regression. In addition, we provided a case of the spatial average for the regressed MPF on May 17 during 2003-2011 (Figure 18). It shows an overestimation compared with other MPF data (DNN_MPF, UH_MPFv2 and UB_MPF), i.e., in Hudson Bay and the band of Beaufort, Chukchi, and East Siberian seas. The regressed MPF is over 30\% even $40 \%$ for some areas in the $12.5 \mathrm{~km}$ grid, which is not possible for the early melting season. These experiments show that the DNN identifies a more complex physical relationship between the MPF and surface reflectance than the simple approaches.

Table 6. Performance of the estimated MPF (the average of the observed MPF with 10 groups of random noises added) against the observed MPF.

\begin{tabular}{ccccc}
\hline Groups & $\mathbf{R}$ & RMSE (\%) & Mean (\%) & Standard Deviation (\%) \\
\hline 1 & -0.0080 & 15.63 & 18.11 & 10.97 \\
2 & -0.0295 & 15.80 & 18.09 & 10.97 \\
3 & -0.0096 & 15.63 & 18.06 & 10.94 \\
4 & 0.0067 & 15.74 & 18.04 & 11.28 \\
5 & 0.0049 & 15.56 & 18.10 & 11.01 \\
6 & -0.0159 & 15.71 & 18.12 & 10.99 \\
7 & 0.0035 & 15.44 & 17.99 & 10.83 \\
8 & 0.0155 & 15.56 & 18.12 & 11.13 \\
9 & 0.0028 & 15.62 & 18.02 & 11.07 \\
10 & 0.0028 & 15.61 & 18.16 & 11.06 \\
\hline
\end{tabular}



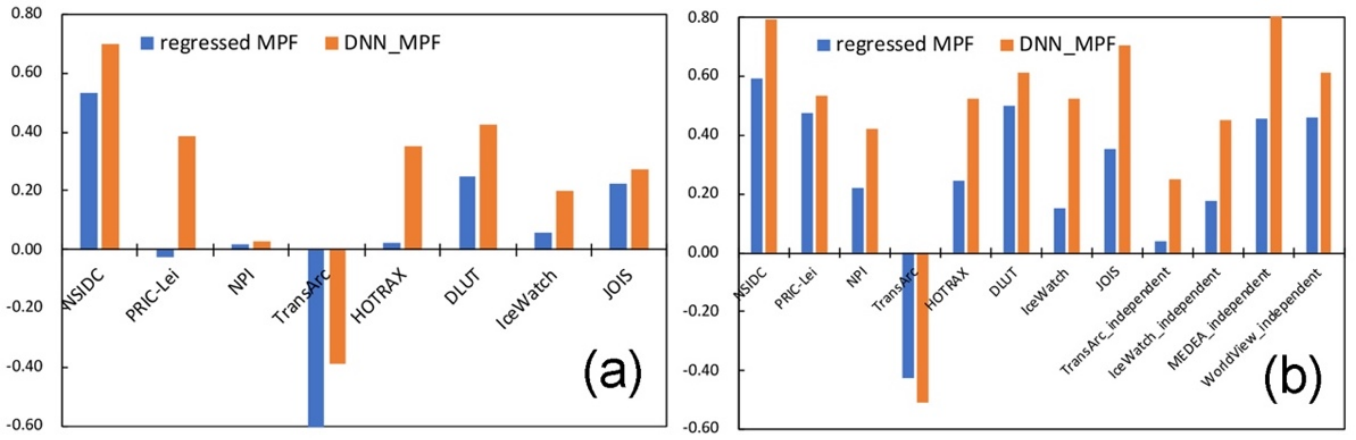

Figure 17. Correlation coefficients of the regressed MPF (regressed by surface reflectance) and DNN_MPF against the observed MPF in a (a) $500 \mathrm{~m}$ grid and (b) $12.5 \mathrm{~km}$ grid.
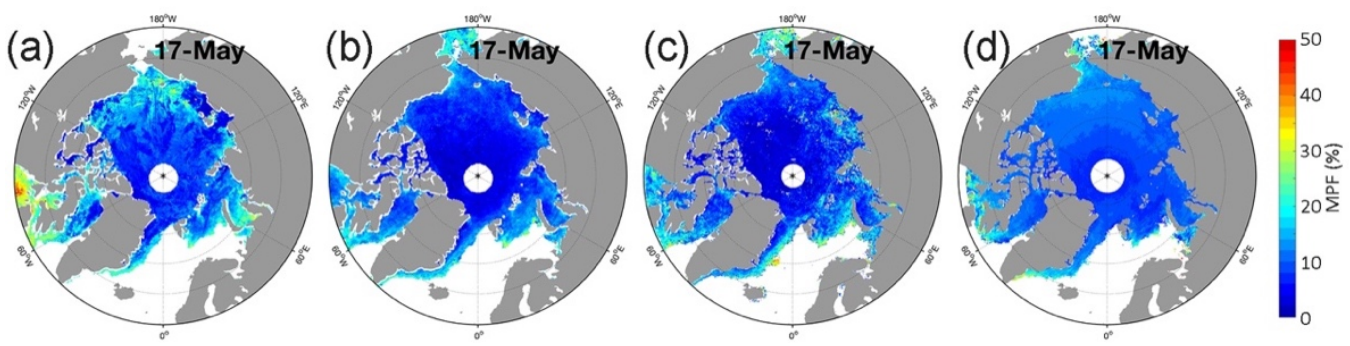

Figure 18. Spatial averaged MPFs on May 17 during 2003-2011. (a) Regressed MPF (regressed by surface reflectance), (b) DNN_MPF, (c) UH_MPFv2, (d) UB_MPF.

The summer passive microwave SIC, i.e., NASA Team SIC, is not accurate due to the effect of melt ponds. According to NSIDC, the total concentration of the NASA Team SIC is within $+/-15 \%$ in the Arctic during summer due to melt ponds (https://nsidc.org/data/nsidc-0051). Kern et al. [71] also pointed out that the NASA Team SIC has a large underestimation in the grids with MPF above $40 \%$. However, we used the MPF retrieved from the network DNN_MPF+ObsSIC, which do not contain the passive microwave SIC. The SIC used in the DNN_MPF+ObsSIC training is the observed SIC from the same sources as the observed MPF. The observed SIC are not retrieved from the passive microwave data, but from the satellite visible band imagery, airborne, ship-based, and in-situ observations. In addition, we made further experiments to compare the MPF retrieved from the networks which, respectively, use NASA Team SIC and revised NASA Team SIC as the target. The random noises ranging from $-15 \%$ to $+15 \%$ are added to the NASA Team SIC, which is regarded as the revised NASA Team SIC (note: we only consider the SIC above $30 \%$. If the revised SIC is above $100 \%$, then we use $100 \%$ ). The results show that the correlation coefficients and RMSE of the MPFs from the two networks are 0.996 and 0.006. This suggests the two MPFs are very similar and the inaccurate SIC has little impact on the MPF retrieval in our method.

According to the comparison of our MPF dataset with the previous UH_MPFv2 and UB_MPF datasets, the three MPF data in early May seem to be higher than actual condition ( $7.6 \%$ for DNN_MPF, 8.3\% for UH_MPFv2, and 9.4\% for UB_MPF during 2003-2011). To address this, we trained the network by only using the surface reflectance in clear sky (DNN_MPF_ClearSky), and compared the results with the current MPF, which is based on both clear and cloudy conditions. As shown in Table 7, the MPF can be reduced by $0.5-3.2 \%$ during 2003-2011 by using the DNN_MPF_ClearSky. This suggests that the higher MPF in May is in part due to the effect of clouds, which influences the input of the surface reflectance. We then examined the spatial difference between the two MPFs in May. The results suggest the current MPF is 0-4\% larger than that of DNN_MPF_ClearSky in some regions during 2000-2019. Although the amount of MPF in May can be reduced by using DNN_MPF_ClearSky, there are lots of missing data in the Arctic, as shown in Figure 19. For the DNN_MPF_ClearSky, we only retained the grids in $12.5 \mathrm{~km}$ which contain more than $90 \%$ clear sky grids in $500 \mathrm{~m}$. This largely limits its 
application to retrieve the MPF. In this study, we attempted to obtain the MPF covering the entire Arctic, therefore we did not choose to use the network only based on clear sky to retrieve the MPF.

Table 7. Comparison of the retrieved MPFs relative to grid in early to middle May during 2003-2011.

\begin{tabular}{|c|c|c|c|c|c|c|c|c|}
\hline \multirow{2}{*}{ Year } & \multicolumn{4}{|c|}{ May 09} & \multicolumn{4}{|c|}{ May 17} \\
\hline & DNN_MPF & DNN_MPF_ClearSky & UH_MPFv2 & UB_MPF & DNN_MPF & DNN_MPF_ClearSky & UH_MPFv2 & UB_MPF \\
\hline 2003 & 7.65 & 5.70 & 5.26 & 9.00 & 9.07 & 7.00 & 7.83 & 9.68 \\
\hline 2004 & 8.04 & 4.81 & 5.26 & 8.98 & 7.75 & 5.50 & 5.94 & 10.30 \\
\hline 2006 & 8.50 & 6.94 & 9.55 & 9.70 & 8.72 & 7.75 & 10.36 & 9.94 \\
\hline 2007 & 8.10 & 6.20 & 9.82 & 9.95 & 7.33 & 6.80 & 8.83 & 10.89 \\
\hline 2008 & 7.61 & 6.10 & 9.06 & 7.60 & 8.06 & 6.60 & 8.15 & 8.69 \\
\hline 2011 & 6.84 & 5.73 & 9.40 & 9.15 & 7.81 & 7.34 & 8.89 & 9.51 \\
\hline Average & 7.63 & 5.97 & 8.29 & 9.43 & 8.12 & 6.96 & 8.44 & 10.05 \\
\hline
\end{tabular}

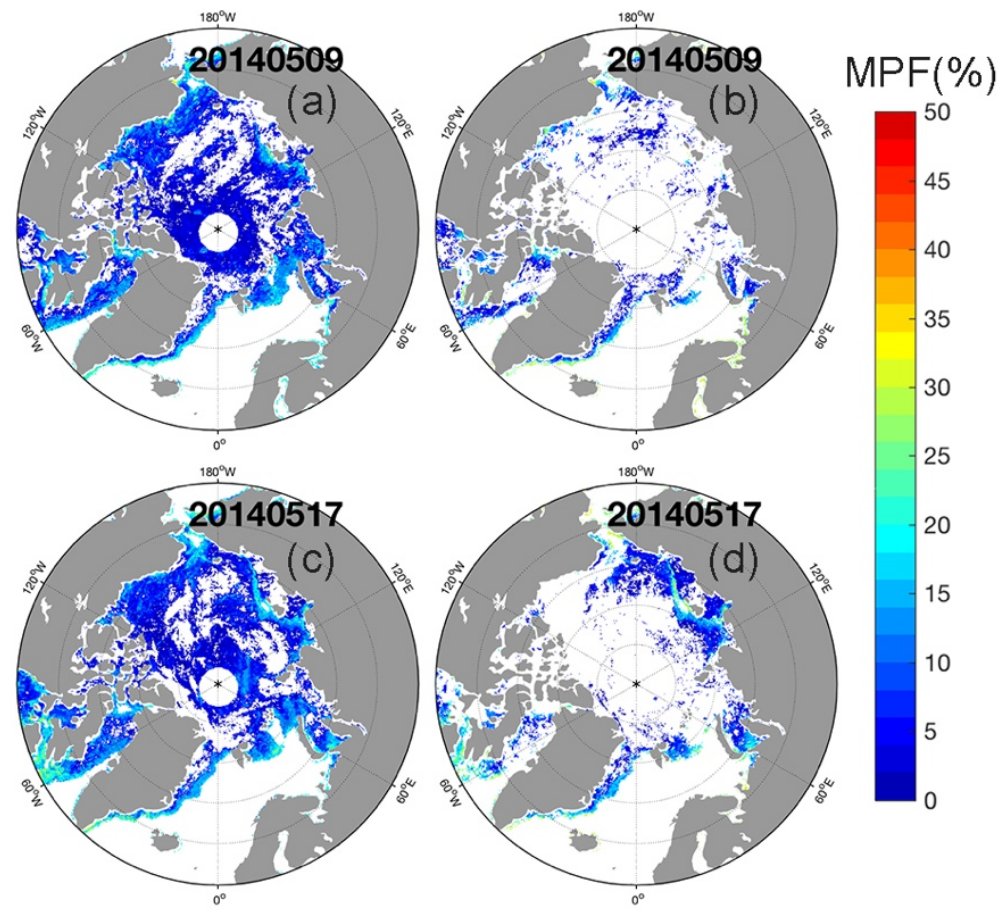

Figure 19. Spatial distribution of the MPF in the first two 8-day periods of 2014. (a,c) DNN_MPF. (b,d) DNN_MPF_ClearSky.

Previous studies $[44,72,73]$ suggested that except for the surface reflectance, the emissivity can also be used to detect the melt ponds. The passive microwave emissivity is influenced by melt ponds in summer [72]. Mathew et al. [73] showed that although the emissivity of multiyear ice remains similar for most months, it varies a lot in summer months (June and July) as a result of the melt pond formation. Tanaka et al. [44] also pointed out that the brightness temperatures in 6.9 and $18.7 \mathrm{GHz}$ decrease with the MPF due to the lower emissivity of water than ice, while the brightness temperatures in $89 \mathrm{GHz}$ increase with the MPF due to the higher emissivity of water than dry MYI. These suggest it is possible to use the emissivity to derive the MPF, but this needs experiments to demonstrate the effective frequencies. Tanaka et al. [44] pointed out that the AMSR-E brightness temperatures with $6 \mathrm{GHz} \mathrm{H}$ and $89 \mathrm{GHz} \mathrm{V}$ are sensitive to the MPF. Studies also showed other parameters, i.e., surface temperature, winds, and roughness, can affect the emissivity in MPF retrieval [74,75]. The frozen melt ponds in late summer might be regarded as ice, due to the similar emissivity of the two types [44]. The MODIS emissivity products (MOD11 and MOD21) have a large data gap in the polar region due to the constraints in the retrieval algorithm, including the solar zenith angle, the time difference between the day and night observations, and the threshold of the brightness temperatures. As a result, we did 
not use the MODIS emissivity data to retrieve the MPF in this study. However, this work can be done by undertaking experiments using other emissivity data in the future.

\section{Conclusions}

In this study, we developed a new method for retrieving MPF over sea ice on the Arctic-wide scale. We developed an ensemble-based DNN and used MODIS surface reflectance from all seven bands as the input data and in-situ observations of MPF from multiple sources as the target data. It was shown that our ensemble-based DNN is robust, which is not sensitive to initially assigned weight and bias. To assess the potential effect of adding SIC as the target on the MPF retrieval, we separately trained the networks that include SIC from three independent sources as the target data. The MPFs retrieved from these networks are similar. This suggests that the SIC target data has a minor effect on the MPF retrieval in our method. We further carried out detailed validation of our MPF retrieval against the in-situ observations, including independent observations. For the initial MPF retrieval on the $500 \mathrm{~m}$ polar stereographic grid, the RMSE were below 0.1 against most of the observations. This was proposed as an important factor to evaluate the accuracy of MPF [34]. The final MPF data on the $12.5 \mathrm{~km}$ polar stereographic grid also suggested our MPF retrieval was in good agreement with the observations, including independent validation data. The correlation coefficients of the final MPF data against the observations were mostly higher than that of the previously published data [35]. Based on this, we created a new data set of MPF from 2000 to 2019. We are currently attempting to make the data in near-real time and available to the research community.

We compared our MPF data to the previously published MPF datasets (UH_MPFv2,UB_MPF) during 2003-2011. In general, the three MPFs show good agreement in terms of the evolution of the MPF throughout the melting season. However, our MPF and UH_MPFv2 increase relatively slower than UB_MPF in June. The UB_MPF reaches the maximum in early July, but our MPF and UH_MPFv2 reach the peak about two 8-day periods later. During the later melting season, the UH_MPFv2 is significantly higher than the other two data and also maintains at the high fraction for a longer time. Our MPF during this period is between the UH_MPFv2 and UB_MPF. We further compared the evolution of the three retrieved MPFs to the observations. The results suggest our MPF is generally closer to the observations than the other two data throughout the melting season.

As mentioned previously, a few efforts have been taken to generate the Arctic wide MPF from the MODIS and MERIS data. However, these data are only available until 2011. Here we created a new data set of MPF from 2000 to 2019, which is the longest MPF data in our knowledge. Previous studies showed the MPF is a good predictor of the September Arctic sea ice extent [29,30]. However, the satellite-based MPF suggests a prediction time of one month later than the model-based MPF for the sea ice extent. This dataset, which has a longer temporal coverage, can validate the prediction time and further confirm the predictive ability of MPF for the sea ice extent in recent years. This new data can also be used to evaluate melt pond parameterizations in sea ice models. So far, the MPF has not been assimilated into sea ice models yet. The assimilation of melt ponds in dynamical models may help to improve the prediction of the Arctic sea ice extent [76].

Supplementary Materials: The following are available online at http://www.mdpi.com/2072-4292/12/17/2746/s1, Figure S1. Cases of the observed MPF from NSIDC overlaid on NASA Team SIC, Figure S2. Cases of the observed MPF from PRIC-Lei overlaid on NASA Team SIC, Figure S3. Cases of the observed MPF from NPI overlaid on NASA Team SIC, Figure S4. Cases of the observed MPF from TransArc overlaid on NASA Team SIC, Figure S5. Cases of the observed MPF from HOTRAX overlaid on NASA Team SIC, Figure S6. Cases of the observed MPF from DLUT overlaid on NASA Team SIC, Figure S7. Cases of the observed MPF from IceWatch overlaid on NASA Team SIC, Figure S8. Cases of the observed MPF from JOIS overlaid on NASA Team SIC, Figure S9. Observed MPF from (a) MEDEA and (b) WorldView against the Observed SIC, Table S1. Correlation coefficients and RMSE in total, training, validation, and test dataset for each observation in $500 \mathrm{~m}$ grid, Table S2. RMS of the observed MPF and RMSE of the DNN_MPF against the observed MPF.

Author Contributions: Y.D. developed and analyzed the data; Y.D. and J.L. wrote the manuscript; J.L. and X.C. designed the experiments and investigated the results; F.H., Z.W. and S.C. discussed the results. All authors 
provided substantial input to the interpretation of the results. All authors have read and agreed to the published version of the manuscript.

Funding: This research is supported by the National Key R\&D Program of China (2018YFA0605901 and 2016YFC1402704), the NSFC (41676185), the Joint PhD Program of China Scholarship Council and the NOAA Climate Program Office (NA15OAR4310163).

Acknowledgments: We thank NSIDC for providing the NSDIC data, Ruibo Lei from the Polar Research Institute of China for providing the PRIC-Lei data, Dmitry Divine and Mats Granskog at the Norwegian Polar Institute for providing the NPI data, Marcel Nicolaus at the Alfred Wegener Institute for Polar and Marine Research for providing the TransArc data, Donald Perovich at the Cold Regions Research and Engineering Laboratory for providing the HOTRAX data, Lu Peng at the Dalian University of Technology for providing the DLUT data, IceWatch Community for providing the IceWatch data, Yasuhiro Tanaka from Kitami Institute of Technology, Japan, for providing the JOIS data, Polar Science Center in University of Washington, for providing the MEDEA data, and Nicholas C. Wright from Thayer School of Engineering, Dartmouth College, for providing the WorldView data.

Conflicts of Interest: The authors declare no conflict of interest.

\section{References}

1. Yackel, J.J.; Barber, D.G.; Hanesiak, J.M. Melt ponds on sea ice in the Canadian Archipelago: 1. Variability in morphological and radiative properties. J. Geophys. Res. Oceans 2000, 105, 22049-22060. [CrossRef]

2. Sturm, M.; Holmgren, J.; Perovich, D.K. Winter snow cover on the sea ice of the Arctic Ocean at the Surface Heat Budget of the Arctic Ocean (SHEBA): Temporal evolution and spatial variability. J. Geophys. Res. Oceans 2002, 107, 8047. [CrossRef]

3. Eicken, H.; Grenfell, T.C.; Perovich, D.K.; Richter-Menge, J.A.; Frey, K. Hydraulic controls of summer Arctic pack ice albedo. J. Geophys. Res. Oceans 2004, 109, C08007. [CrossRef]

4. Perovich, D.K.; Polashenski, C. Albedo evolution of seasonal Arctic sea ice. Geophys. Res. Lett. 2012, 39, L08501. [CrossRef]

5. Polashenski, C.; Perovich, D.; Courville, Z. The mechanisms of sea ice melt ponds formation and evolution. J. Geophys. Res. Oceans 2012, 117, C01001. [CrossRef]

6. Tschudi, M.A.; Curry, J.A.; Maslanik, J.A. Airborne observations of summertime surface features and their effect on surface albedo during FIRE/SHEBA. J. Geophys. Res. Atmos. 2001, 106, 15335-15344. [CrossRef]

7. Perovich, D.K.; Grenfell, T.C.; Light, B.; Hobbs, P.V. Seasonal evolution of the albedo of multiyear Arctic sea ice. J. Geophys. Res. Oceans 2002, 107, 8044. [CrossRef]

8. Webster, M.A.; Rigor, I.G.; Perovich, D.K.; Richter-Menge, J.A.; Polashenski, C.M.; Light, B. Seasonal evolution of melt ponds on Arctic sea ice. J. Geophys. Res. Oceans 2015, 120, 5968-5982. [CrossRef]

9. Curry, J.A.; Schramm, J.L.; Ebert, E.E. Sea ice-albedo climate feedback mechanism. J. Clim. 1995, 8, $240-247$. [CrossRef]

10. Perovich, D.K.; Tucker, W.B. Arctic sea-ice conditions and the distribution of solar radiation during summer. Ann. Glaciol. 1997, 25, 445-450. [CrossRef]

11. Perovich, D.K.; Light, B.; Eicken, H.; Jones, K.F.; Runciman, K.; Nghiem, S.V. Increasing solar heating of the Arctic Ocean and adjacent seas, 1979-2005: Attribution and role in the ice-albedo feedback. Geophys. Res. Lett. 2007, 34, L19505. [CrossRef]

12. Anderson, M.R.; Drobot, S.D. Spatial and temporal variability in snowmelt onset over Arctic sea ice. Ann. Glaciol. 2001, 33, 74-78. [CrossRef]

13. Perovich, D.K.; Nghiem, S.V.; Markus, T.; Schweiger, A. Seasonal evolution and interannual variability of the local solar energy absorbed by the Arctic sea ice-ocean system. J. Geophys. Res. Oceans 2007, 112, C03005. [CrossRef]

14. Tschudi, M.A.; Maslanik, J.A.; Perovich, D.K. Derivation of melt ponds coverage on Arctic sea ice using MODIS observations. Remote Sens. Environ. 2008, 112, 2605-2614. [CrossRef]

15. Holland, M.M.; Bailey, D.A.; Briegleb, B.P.; Light, B.; Hunke, E. Improved sea ice shortwave radiation physics in CCSM4: The impact of melt ponds and aerosols on Arctic sea ice. J. Clim. 2012, 25, 1413-1430. [CrossRef]

16. Nicolaus, M.; Katlein, C.; Maslanik, J.; Hendricks, S. Changes in Arctic sea ice result in increasing light transmittance and absorption. Geophys. Res. Lett. 2012, 39, L24501. [CrossRef]

17. Nicolaus, M.; Katlein, C.; Maslanik, J.; Hendricks, S. Correction to "Changes in Arctic sea ice result in increasing light transmittance and absorption". Geophys. Res. Lett. 2013, 40, 2699-2700. [CrossRef] 
18. Arrigo, K.R.; Perovich, D.K.; Pickart, R.S.; Brown, Z.W.; Van Dijken, G.L.; Lowry, K.E.; Bates, N.R. Massive phytoplankton blooms under Arctic sea ice. Science 2012, 1215065. [CrossRef]

19. Palmer, M.A.; Saenz, B.T.; Arrigo, K.R. Impacts of sea ice retreat, thinning, and melt-pond proliferation on the summer phytoplankton bloom in the Chukchi Sea, Arctic Ocean. Deep Sea Res. Part II 2014, 105, 85-104. [CrossRef]

20. Arctic Climate Impact Assessment (ACIA). Impacts of a Warming Arctic; Cambridge University Press: Cambridge, UK, 2004; 140p.

21. Serreze, M.C.; Francis, J.A. The Arctic amplification debate. Clim. Chang. 2006, 76, 241-264. [CrossRef]

22. IPCC. Summary for Policymakers. In Climate Change 2013. The Physical Science Basis, Contribution of Working Group I to the Fifth Assessment Report of the Intergovernmental Panel on Climate Change; Cambridge University Press: Cambridge, UK, 2013.

23. Stroeve, J.C.; Serreze, M.C.; Holland, M.M.; Kay, J.E.; Malanik, J.; Barrett, A.P. The Arctic's rapidly shrinking sea ice cover: A research synthesis. Clim. Chang. 2012, 110, 1005-1027. [CrossRef]

24. Comiso, J.C.; Parkinson, C.L.; Gersten, R.; Stock, L. Accelerated decline in the Arctic sea ice cover. Geophys. Res. Lett. 2008, 35, L01703. [CrossRef]

25. Serreze, M.C.; Stroeve, J. Arctic sea ice trends, variability and implications for seasonal ice forecasting. Philos. Trans. R. Soc. A Math. Phys. Eng. Sci. 2015, 373, 20140159. [CrossRef] [PubMed]

26. Huang, W.; Lu, P.; Lei, R.; Xie, H.; Li, Z. Melt pond distribution and geometry in high Arctic sea ice derived from aerial investigations. Ann. Glaciol. 2016, 57, 105-118. [CrossRef]

27. Hutchings, J.K.; Faber, M.K. Sea-Ice Morphology Change in the Canada Basin Summer: 2006-2015 Ship Observations Compared to Observations From the 1960s to the Early 1990s. Front. Earth Sci. 2018, 6, 123. [CrossRef]

28. Rösel, A.; Kaleschke, L. Exceptional melt pond occurrence in the years 2007 and 2011 on the Arctic sea ice revealed from MODIS satellite data. J. Geophys. Res. Oceans 2012, 117. [CrossRef]

29. Schröder, D.; Feltham, D.L.; Flocco, D.; Tsamados, M. September Arctic sea-ice minimum predicted by spring melt-pond fraction. Nat. Clim. Chang. 2014, 4, 353-357. [CrossRef]

30. Liu, J.; Song, M.; Horton, R.M.; Hu, Y. Revisiting the potential of melt ponds fraction as a predictor for the seasonal Arctic sea ice extent minimum. Environ. Res. Lett. 2015, 10, 054017. [CrossRef]

31. Markus, T.; Cavalieri, D.J.; Ivanoff, A. The potential of using Landsat 7 ETM+ for the classification of sea-ice surface conditions during summer. Ann. Glaciol. 2002, 34, 415-419. [CrossRef]

32. Markus, T.; Cavalieri, D.J.; Tschudi, M.A.; Ivanoff, A. Comparison of aerial video and Landsat 7 data over ponded sea ice. Remote Sens. Environ. 2003, 86, 458-469. [CrossRef]

33. Rösel, A.; Kaleschke, L.; Birnbaum, G. Melt ponds on Arctic sea ice determined from MODIS satellite data using an artificial neural network. Cryosphere 2012, 6, 431-446. [CrossRef]

34. Wright, N.C.; Polashenski, C.M. How machine learning and high-Resolution imagery can improve melt pond retrieval from MODIS over current spectral unmixing techniques. J. Geophys. Res. Oceans 2020, e2019JC015569. [CrossRef]

35. Rösel, A.; Kaleschke, L.; Kern, S. Gridded Melt Pond Cover Fraction on Arctic Sea Ice Derived from TERRA-MODIS 8-Day Composite Reflectance Data Bias Corrected Version 02; World Data Center for Climate (WDCC) at DKRZ: Hamburg, Germany, 2015. [CrossRef]

36. Istomina, L.; Heygster, G.; Huntemann, M.; Schwarz, P.; Birnbaum, G.; Scharien, R.; Polashenski, C.; Perovich, D.; Zege, E.; Malinka, A.; et al. Melt ponds fraction and spectral sea ice albedo retrieval from MERIS data-Part 1: Validation against in situ, aerial, and ship cruise data. Cryosphere 2015, 9, 1551-1566. [CrossRef]

37. Zege, E.; Malinka, A.; Katsev, I.; Prikhach, A.; Heygster, G.; Istomina, L.; Birnbaum, G.; Schwarz, P. Algorithm to retrieve the melt ponds fraction and the spectral albedo of Arctic summer ice from satellite optical data. Remote Sens. Environ. 2015, 163, 153-164. [CrossRef]

38. Kim, D.J.; Hwang, B.; Chung, K.H.; Lee, S.H.; Jung, H.S.; Moon, W.M. Melt ponds mapping with high-resolution SAR: The first view. Proc. IEEE 2013, 101, 748-758. [CrossRef]

39. Scharien, R.K.; Hochheim, K.; Landy, J.; Barber, D.G. First-year sea ice melt ponds fraction estimation from dual-polarisation C-band SAR-Part 2: Scaling in situ to Radarsat-2. Cryosphere 2014, 8, 2163-2176. [CrossRef] 
40. Scharien, R.K.; Landy, J.; Barber, D.G. First-year sea ice melt ponds fraction estimation from dual-polarisation C-band SAR_Part 1: In situ observations. Cryosphere 2014, 8, 2147-2162. [CrossRef]

41. Mäkynen, M.; Kern, S.; Rösel, A.; Pedersen, L.T. On the estimation of melt ponds fraction on the Arctic Sea ice with ENVISAT WSM images. IEEE Trans. Geosci. Remote Sens. 2014, 52, 7366-7379. [CrossRef]

42. Han, H.; Im, J.; Kim, M.; Sim, S.; Kim, J.; Kim, D.J.; Kang, S.H. Retrieval of melt ponds on arctic multiyear sea ice in summer from terrasar-x dual-polarization data using machine learning approaches: A case study in the chukchi sea with mid-incidence angle data. Remote Sens. 2016, 8, 57. [CrossRef]

43. Li, H.; Perrie, W.; Li, Q.; Hou, Y. Estimation of melt ponds fractions on first year sea ice using compact polarization SAR. J. Geophys. Res. Oceans 2017, 122, 8145-8166. [CrossRef]

44. Tanaka, Y.; Tateyama, K.; Kameda, T.; Hutchings, J.K. Estimation of melt ponds fraction over high-concentration Arctic sea ice using AMSR-E passive microwave data. J. Geophys. Res. Oceans 2016, 121, 7056-7072. [CrossRef]

45. Wright, N.C.; Polashenski, C.M. Open-source algorithm for detecting sea ice surface features in high-resolution optical imagery. Cryosphere 2018, 12, 1307-1329. [CrossRef]

46. Chang, D.H.; Islam, S. Estimation of soil physical properties using remote sensing and artificial neural network. Remote Sens. Environ. 2000, 74, 534-544. [CrossRef]

47. Hong, Y.; Hsu, K.L.; Sorooshian, S.; Gao, X. Precipitation estimation from remotely sensed imagery using an artificial neural network cloud classification system. J. Appl. Meteorol. 2004, 43, 1834-1853. [CrossRef]

48. Yu, X.; Wu, X.; Luo, C.; Ren, P. Deep learning in remote sensing scene classification: A data augmentation enhanced convolutional neural network framework. GISci. Remote Sens. 2017, 54, 741-758. [CrossRef]

49. Liu, Q.; Zhang, Y.; Lv, Q.; Shang, L. Applying High-Resolution Visible Imagery to Satellite Melt ponds Fraction Retrieval: A Neural Network Approach. arXiv 2017, arXiv:1704.04281. [CrossRef]

50. Lee, S.; Stroeve, J.; Tsamados, M.; Khan, A.L. Machine learning approaches to retrieve pan-Arctic melt ponds from visible satellite imagery. Remote Sens. Environ. 2020, 247, 111919. [CrossRef]

51. Liu, J.; Zhang, Y.; Cheng, X.; Hu, Y. Retrieval of Snow Depth over Arctic Sea Ice Using a Deep Neural Network. Remote Sens. 2019, 11, 2864. [CrossRef]

52. Vermote, E. MOD09A1 MODIS/Terra Surface Reflectance 8-Day L3 Global 500 m SIN Grid V006; NASA EOSDIS LP DAAC: Washington, DC, USA, 2015. [CrossRef]

53. Fetterer, F.; Wilds, S.; Sloan, J. Arctic Sea Ice Melt Ponds Statistics and Maps, 1999-2001, Version 1; NSIDC: National Snow and Ice Data Center: Boulder, CO, USA, 2018. [CrossRef]

54. NSIDC. SHEBA Reconnaissance Imagery, Version 1.0; National Snow and Ice Data Center: Boulder, CO, USA, 2000.

55. Fetterer, F.; Untersteiner, N. Observations of Melt Ponds on Arctic Sea Ice. J. Geophys. Res. 1998, 103, 24821-24835. [CrossRef]

56. Lei, R.; Tian-Kunze, X.; Li, B.; Heil, P.; Wang, J.; Zeng, J.; Tian, Z. Characterization of summer Arctic sea ice morphology in the $135^{\circ}-175^{\circ} \mathrm{W}$ sector using multi-scale methods. Cold Reg. Sci. Technol. 2017, 133, 108-120. [CrossRef]

57. Divine, D.V.; Granskog, M.A.; Hudson, S.R.; Pedersen, C.A.; Karlsen, T.I.; Divina, S.A.; Renner, A.H.H.; Gerland, S. Regional melt-pond fraction and albedo of thin Arctic first-year drift ice in late summer. Cryosphere 2015, 9, 255-268. [CrossRef]

58. Divine, D.V.; Pedersen, C.A.; Karlsen, T.I.; Aas, H.F.; Granskog, M.A.; Hudson, S.R.; Gerland, S. Photogrammetric retrieval and analysis of small scale sea ice topography during summer melt. Cold Reg. Sci. Technol. 2016, 129, 77-84. [CrossRef]

59. Nicolaus, M.; Katlein, C.; Maslanik, J.A.; Hendricks, S. Sea Ice Conditions during the POLARSTERN Cruise ARK-XXVI/3 (TransArc) in 2011; PANGAEA Dataset, PANGAEA; Alfred Wegener Institute, Helmholtz Center for Polar and Marine Research: Bremerhaven, Germany, 2012. [CrossRef]

60. Perovich, D.K.; Grenfell, T.C.; Light, B.; Elder, B.C.; Harbeck, J.; Polashenski, C.; Tucker, W.B.; Stelmach, C. Transpolar observations of the morphological properties of Arctic sea ice. J. Geophys. Res. Oceans 2009, 114, C00A04. [CrossRef]

61. Lu, P.; Li, Z.; Cheng, B.; Lei, R.; Zhang, R. Sea ice surface features in Arctic summer 2008: Aerial observations. Remote Sens. Environ. 2010, 114, 693-699. [CrossRef] 
62. Cavalieri, D.J.; Parkinson, C.L.; Gloersen, P.; Zwally, H.J. Sea Ice Concentrations from Nimbus-7 SMMR and DMSP SSM/I-SSMIS Passive Microwave Data, Version 1 (Updated Yearly); NASA National Snow and Ice Data Center Distributed Active Archive Center: Boulder, CO, USA, 1996. [CrossRef]

63. Wright, N.C.; Polashenski, C.M. Surface Classifications of Arctic Sea Ice from WorldView Satellite Imagery. Arctic Ocean, 2010-2015; Arctic Data Center, 2019. Available online: https://arcticdata.io/ (accessed on 20 March 2020). [CrossRef]

64. Spreen, G.; Kaleschke, L.; Heygster, G. Sea ice remote sensing using AMSR-E 89 GHz channels. J. Geophys. Res. 2008, 113, C02S03. [CrossRef]

65. Olden, J.D.; Jackson, D.A. Illuminating the "black box": A randomization approach for understanding variable contributions in artificial neural networks. Ecol. Model. 2002, 154, 135-150. [CrossRef]

66. Gevrey, M.; Dimopoulos, I.; Lek, S. Review and comparison of methods to study the contribution of variables in artificial neural network models. Ecol. Model. 2003, 160, 249-264. [CrossRef]

67. Ortiz, M.D. Remote Sensing of Open Water Fraction and Melt Ponds in the Beaufort Sea Using Machine Learning Algorithms; University of Miami: Coral Gables, FL, USA, 2017.

68. Zhang, J.; Schweiger, A.; Webster, M.; Light, B.; Steele, M.; Ashjian, C.; Campbell, R.; Spitz, Y. Melt pond conditions on declining Arctic sea ice over 1979-2016: Model development, validation, and results. J. Geophys. Res. Oceans 2018, 123, 7983-8003. [CrossRef]

69. Wright, N.C. Novel Algorithms to Analyze Remotely Sensed Optical Imagery Reveal New Behavior of Sea Ice Melt Ponds. Ph.D. Thesis, Dartmouth College, Hanover, NH, USA, 2020.

70. Gallaher, S.G. The importance of capturing late melt season sea ice conditions for modeling the western Arctic ocean boundary layer. Elem. Sci. Anthr. 2019, 7, 53. [CrossRef]

71. Kern, S.; Rösel, A.; Pedersen, L.T.; Ivanova, N.; Saldo, R.; Tonboe, R.T. The impact of melt ponds on summertime microwave brightness temperatures and sea-ice concentrations. Cryosphere 2016, 10, 2217-2239. [CrossRef]

72. Eppler, D.T.; Farmer, L.D.; Lohanick, A.W.; Anderson, M.R.; Cavalieri, D.J.; Comiso, J.; Maslanik, J.A. Passive microwave signatures of sea ice. In Microwave Remote Sensing of Sea Ice; American Geophysical Union: Washington, DC, USA, 1992; Volume 68, pp. 47-71.

73. Mathew, N.; Heygster, G.; Melsheimer, C. Surface emissivity of the Arctic sea ice at AMSR-E frequencies. IEEE Trans. Geosci. Remote Sens. 2009, 47, 4115-4124. [CrossRef]

74. Eicken, H.; Krouse, H.R.; Kadko, D.; Perovich, D.K. Tracer studies of pathways and rates of meltwater transport through Arctic summer sea ice. J. Geophys. Res. Oceans 2002, 107, SHE-22. [CrossRef]

75. Perovich, D.K.; Grenfell, T.C.; Richter-Menge, J.A.; Light, B.; Tucker, W.B.; Eicken, H. Thin and thinner: Sea ice mass balance measurements during SHEBA. J. Geophys. Res. Oceans 2003, 108. [CrossRef]

76. Liu, J.; Chen, Z.; Hu, Y.; Zhang, Y.; Ding, Y.; Cheng, X.; Yang, Q.; Nerger, L.; Spreen, G.; Horton, R.; et al. Towards reliable Arctic sea ice prediction using multivariate data assimilation. Sci. Bull. 2019, 64, 63-72. [CrossRef]

(C) 2020 by the authors. Licensee MDPI, Basel, Switzerland. This article is an open access article distributed under the terms and conditions of the Creative Commons Attribution (CC BY) license (http://creativecommons.org/licenses/by/4.0/). 